\title{
Élastomères pour la réalisation de protections dento-maxillaires : évaluation physique et biologique
}

\section{RÉSUMÉ}

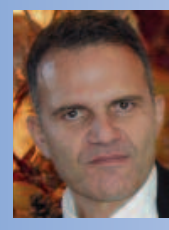

Pascal AUROY

CHU de Clermont-Ferrand,

Service d'Odontologie.

Université d'Auvergne Clermond-Ferrand I,

Faculté de Chirurgie Dentaire.

Laboratoire de recherche clinique

en prothèse odontologique.

11, boulevard Charles-de-Gaulle,

63000 Clermont-Ferrand, France.

Dominique-Jane CHAUVEL-LEBRET

Laboratoire de biomatériaux en site osseux,

UMR CNRS 6226, Université de Rennes I,

UFR Odontologie de Rennes

et Pôle d'Odontologie du CHU de Rennes.

\section{Maurice MORENAS}

Faculté de Chirurgie Dentaire et Service d'Odontologie de Clermont-Ferrand.

Laboratoire de recherche clinique

en prothèse odontologique.

\section{Jean-Luc VEYRUNE}

Faculté de Chirurgie Dentaire et Service d'Odontologie de Clermont-Ferrand.

EA 3847
Les élastomères de silicone présentent des propriétés générales qui les rendent susceptibles d'être utilisés pour la fabrication des protections dento-maxillaires, mais n'ont jamais été envisagés pour cet usage.

Nous avons évalué la dureté shore A et les propriétés d'absorption de chocs de différents élastomères de silicone et de produits dérivés, comparé leurs valeurs avec celles des matériaux utilisés habituellement pour la confection des protections dento-maxillaires et corrélé leur capacité d'absorption et de transmission des chocs à leur dureté shore. Les élastomères de silicone absorbent mieux les chocs que les matériaux habituellement utilisés pour la confection des protections dentomaxillaires.

L'analyse statistique des valeurs de dureté et des forces transmises pour les 27 matériaux testés indique que le maximum de force transmise augmente avec la dureté. Cette relation n'est pas linéaire et la déviation à la linéarité est plus importante pour les valeurs minimales que maximales.

La biocompatibilité théorique des élastomères de silicone, soulignée dans de nombreuses études, a été récemment remise en question. Nous avons donc évalué et comparé la biocompatibilité in vitro de ces matériaux.

Différents tests (à 24 heures et à 72 heures) ont été réalisés pour déterminer la viabilité (le test colorimétrique au MTT) et la prolifération cellulaires (cytométrie en flux). Les effets génotoxiques de ces maté-

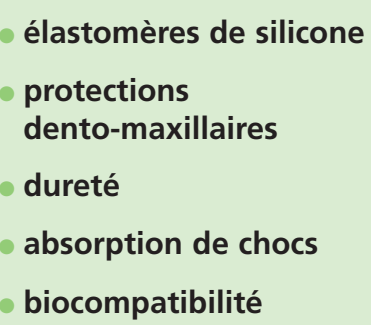


riaux ont été étudiés par la méthode des comètes et les altérations morphologiques évaluées par microscopie à balayage. Un témoin positif (polyuréthane) et négatif (polystyrène de culture) de toxicité ont été inclus dans l'étude.

Pour l'ensemble des échantillons, on assiste, par rapport à la référence polystyrène à une diminution du nombre de cellules entre 24 et 72 heures. Celle-ci est corrélée à une réduction du pourcentage des cellules en phase $\mathrm{S}$.

Les différences observées, concernant la viabilité cellulaire, entre les échantillons et le polystyrène résultent essentiellement $d$ 'un déficit d'adhérence initiale.

Le test des comètes n'a pas pu mettre en évidence de variations significatives entre les divers échantillons testés.

Les élastomères de silicone présentent une biocompatibilité comparable à celle du meilleur des trois produits actuellement commercialisés pour la confection des protections dento-maxillaires, étudiés dans ce travail.

Ces résultats permettent de préconiser l'utilisation de ces élastomères de silicone pour la confection des protections dento-maxillaires.

\section{Introduction}

$>$

L'intérêt du port de prothèses de pré-

vention lors des pratiques sportives a été préalablement démontré $[1,2,3]$. Leurs formes et les différents types de protection ont été discutés dans de nombreux travaux $[2,4,5,6]$. La conception des protections doit prendre en compte les caractéristiques anatomophysiologiques du porteur, ce qui exclut les protections standards ou semi-adaptables [7]. Cinq types de matériaux sont habituellement utilisés pour réaliser des protections dento-maxillaires. Les copolymères de polyvinyl acétate polyéthylène (EVA) et le chlorure de polyvinyl (PVC) sont les plus communément utilisés. Le caoutchouc naturel, les résines acryliques plastifiées et les polyuréthanes sont moins fréquemment utilisés [8].

Les élastomères de silicone n'ont été que rarement suggérés pour cet usage $[4,9,10]$. Pour- tant les élastomères de silicone sont caractérisés par leur grande faculté à absorber l'énergie et à la restituer dans des délais variables, de manière totale ou partielle [11]. De plus, ces matériaux répondent aux critères retenus pour la fabrication des protections dento-maxillaires : biocompatibilité, aptitude au moulage, résistance au déchirement, résistance au choc $[4,12]$. Les élastomères de silicone résultent de I'incorporation de charges dans une matrice polymère synthétique à haut poids moléculaire [11]. Leurs caractéristiques mécaniques peuvent donc être modifiées par adjonction d'huile de silicone réactive ou par incorporation de charges dans le but d'étendre leur indication à la réalisation de protections dento-maxillaires adaptées aux contraintes spécifiques des différentes pratiques sportives. 


\section{Évaluation physique}

L'évaluation des propriétés mécaniques des matériaux destinés à la confection des protections dento-maxillaires repose généralement sur des mesures de dureté, de compression, de traction, d'absorption d'énergie et d'absorption d'eau $[8,10,12,13]$.

Afin de comparer les propriétés des élastomères de silicone bruts ou modifiés à celles des produits standards actuellement utilisés, nous avons évalué leur capacité d'absorption des chocs ainsi que leur dureté shore $A$.

\section{Matériel et méthode}

Les tableaux I et II regroupent les 27 matériaux étudiés comprenant trois élastomères actuellement commercialisés pour la fabrication des protections dento-maxillaires (échantillons 1, 2 et 3), 6 élastomères de silicone bruts (maîtres mélanges) (échantillons de 4 à 9) et
18 élastomères de silicone modifiés (échantillons de 10 à 27).

Les élastomères de silicone modifiés ont été obtenus, soit par adjonction de 10 à $20 \%$ d'huile de silicone réactive de viscosité différente (échantillons 10, 11, 14, 15, 16, 17, 21, 23 et 25), soit par stratification de cinq couches de fibres de verre stratifiées sur une face de la plaque avec ou sans huile de silicone (échantillons 12, 18, 22, 24 et 26), ou encore par incorporation de fibres de verre fragmentées réparties dans la masse de l'échantillon après adjonction de $20 \%$ d'huile de silicone nécessaire à l'incorporation de fibres de verre coupées (échantillons 13, 19, 20 et 27) (tableau III).

Chaque élastomère réticulé en plaque de dimension $130 \times 130$ × 4,50 mm a été ensuite découpé à l'emporte-pièce en 16 pastilles. Parmi celles-ci, six sont réservées aux mesures de la dureté et dix au test de simulation d'impact (fig. 1).

\begin{tabular}{|c|c|c|c|c|}
\hline Matériaux & Nom chimique & $\begin{array}{c}\text { Nom } \\
\text { commercial }\end{array}$ & Fabricant & $\begin{array}{c}\text { Echantillons } \\
\mathbf{N}^{\circ}\end{array}$ \\
\hline \multirow{3}{*}{$\begin{array}{l}\text { Matériaux commercialisés } \\
\text { pour la confection de } \\
\text { protection dento-maxillaire }\end{array}$} & $\begin{array}{l}\text { polyvinylacetate- } \\
\text { polyéthylène }\end{array}$ & Major-Plast & Major (Acigné, France) & 1 \\
\hline & $\begin{array}{l}\text { polyvinylacetate- } \\
\text { polyéthylène }\end{array}$ & Plastulène & $\begin{array}{l}\text { Dental Polymer } \\
\text { (Biella, Italie) }\end{array}$ & 2 \\
\hline & $\begin{array}{l}\text { styrol polyolefin } \\
\text { methyl metacrylate }\end{array}$ & SR-Ivocap & Ivoclar (St-Jorioz, France) & 3 \\
\hline Elastomères de silicone / silbione & polyvinylsiloxane & RTV 71556 & Rhodia (Neuilly/Seine, France) & 4 \\
\hline Elastomères de silicone / silbione & polyvinylsiloxane & RTV 70-147 & Rhodia (Neuilly/Seine, France) & 5 \\
\hline Elastomères de silicone / silbione & polyvinylsiloxane & RTV 70-148 & Rhodia (Neuilly/Seine, France) & 6 \\
\hline Elastomères de silicone / silastic & polyvinylsiloxane & MDX 4-4210 & Dow Corning (Midland, Mich., USA) & 7 \\
\hline Elastomères de silicone / silastic & polyvinylsiloxane & Q7 48-40 & Dow Corning (Midland, Mich., USA) & 8 \\
\hline Elastomères de silicone / silastic & polyvinylsiloxane & Q7 48-65 & Dow Corning (Midland, Mich., USA) & 9 \\
\hline
\end{tabular}




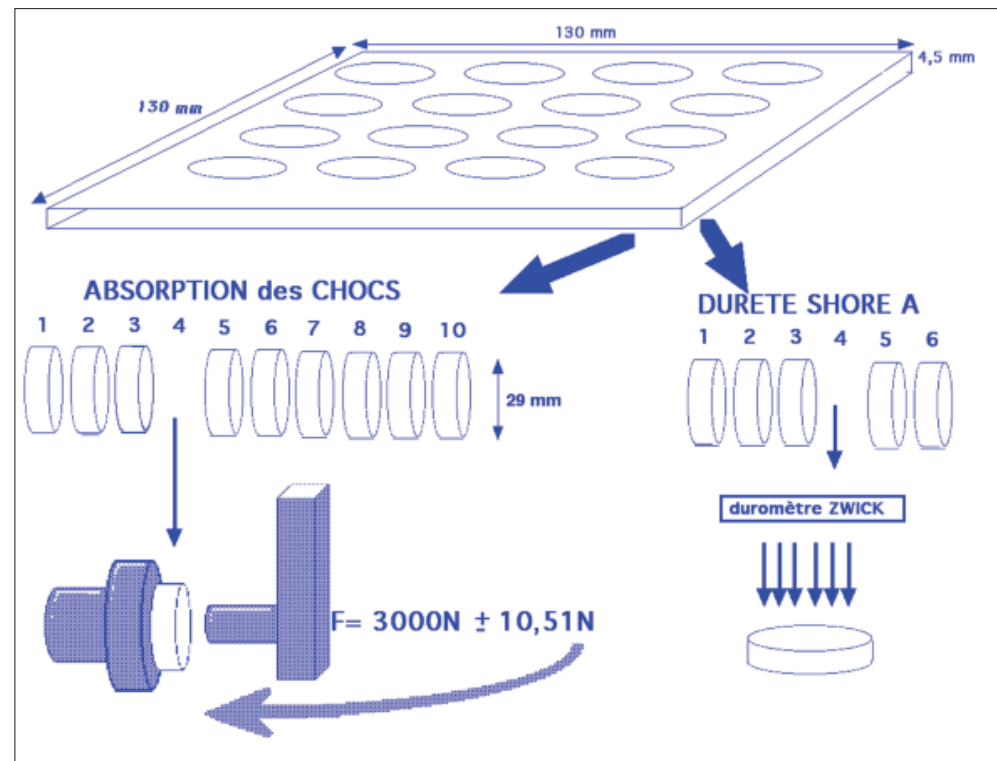

Fig. 1 Préparation des échantillons et regroupement.

Tableau II Composition des 18 échantillons préparés à partir des élastomères de silicone brut par adjonction d'huile de silicone réactive, de fibres de verre stratifiées ou de fibres de verre fragmentées associées à $20 \%$ d'huile de silicone. (La codification des additifs est expliquée dans le tableau III).

\begin{tabular}{|c|c|c|c|}
\hline \multicolumn{2}{|c|}{ ÉLASTOMÈRES DE SILICONE ORIGINAUX } & \multicolumn{2}{|c|}{ ÉLASTOMÈRES DE SILICONE MODIFIÉS } \\
\hline Échantillon $\mathrm{N}^{\circ}$ & Nom commercial & Code de composition & Echantillon $\mathrm{N}^{\circ}$ \\
\hline \multirow{4}{*}{9} & Q7 48-65 & Fluide DC-20 \% & 10 \\
\hline & Q7 48-65 & Fluide DC-10 \% & 11 \\
\hline & Q7 48-65 & Fibres de verre stratifiées & 12 \\
\hline & Q7 48-65 & Fluide DC $20 \%$ + Fibres de verre fragmentées & 13 \\
\hline \multirow{2}{*}{8} & Q7 48-40 & Fluide RP $20 \%$ + Fluide DC $20 \%$ & 14 \\
\hline & Q7 48-40 & Fluide RP $10 \%$ + Fluide DC $10 \%$ & 15 \\
\hline \multirow{4}{*}{7} & MDX-4-4210 & Fluide DC-20 \% & 16 \\
\hline & MDX-4-4210 & Fluide DC-10 \% & 17 \\
\hline & MDX-4-4210 & Fibres de verre stratifiées & 18 \\
\hline & MDX-4-4210 & Fluide DC $20 \%$ + Fibres de verre fragmentées & 19 \\
\hline \multirow{3}{*}{5} & RTV 70-147 & Fluide RP $20 \%$ + Fibres de verre fragmentées & 20 \\
\hline & RTV 70-147 & Fluide RP $20 \%$ & 21 \\
\hline & RTV 70-147 & Fibres de verre stratifiées & 22 \\
\hline \multirow{2}{*}{6} & RTV 70-148 & Fluide RP $20 \%$ & 23 \\
\hline & RTV 70-148 & Fibres de verre stratifiées & 23 \\
\hline \multirow{3}{*}{4} & RTV 71556 & Fluide RP $20 \%$ & 25 \\
\hline & RTV 71556 & Fibres de verre stratifiées & 26 \\
\hline & RTV 71556 & Fluide RP $20 \%$ + Fibres de verre fragmentées & 27 \\
\hline
\end{tabular}




\begin{tabular}{|c|c|c|c|c|}
\hline Type & Référence & Fabricant & Quantité & Code \\
\hline \multirow{4}{*}{$\begin{array}{l}\text { Huile de } \\
\text { silicone }\end{array}$} & H47-V 1000 & Rhodia & $10 \%$ du Poids & Fluide RP-10 \% \\
\hline & H47-V 1000 & Rhodia & $20 \%$ du Poids & Fluide RP-20 \% \\
\hline & DC $200 / 0,65$ cs & Dow-Corning & $10 \%$ du Poids & Fluide DC-10 \% \\
\hline & DC $200 / 0,65$ cs & Dow-Corning & $20 \%$ du Poids & Fluide DC-20\% \\
\hline \multirow{2}{*}{ Fibres de verre } & Sergé $200 \mathrm{~g} / \mathrm{m}^{2}$ & Brochier & 5 couches & Fibres stratifiées \\
\hline & Fibres de verre en vrac $0,8 \mathrm{~cm}$ & Brochier & $50 \%$ du Volume & Fibres fragmentées \\
\hline
\end{tabular}

\section{$>$ Mesure de la dureté}

Pour chaque pastille, cinq mesures de dureté sont réalisées avec un duromètre (Zwick, Willepinden, France) sur l'échelle $A$.

Une moyenne pour chaque pastille est obtenue puis la dureté de chaque échantillon ( \pm erreur standard est calculée à partir des valeurs moyennes des six pastilles.

\section{> Mesure d'absorption des chocs}

La méthodologie mise en œuvre pour les mesures de capacité d'absorption des chocs est illustrée figure 2.

Le banc d'essai utilisé permet la simulation du choc produit par un crampon de chaussure de sport (poinçon cylindrique en acier de $10 \mathrm{~mm}$ de diamètre) sur un échantillon du matériau testé.

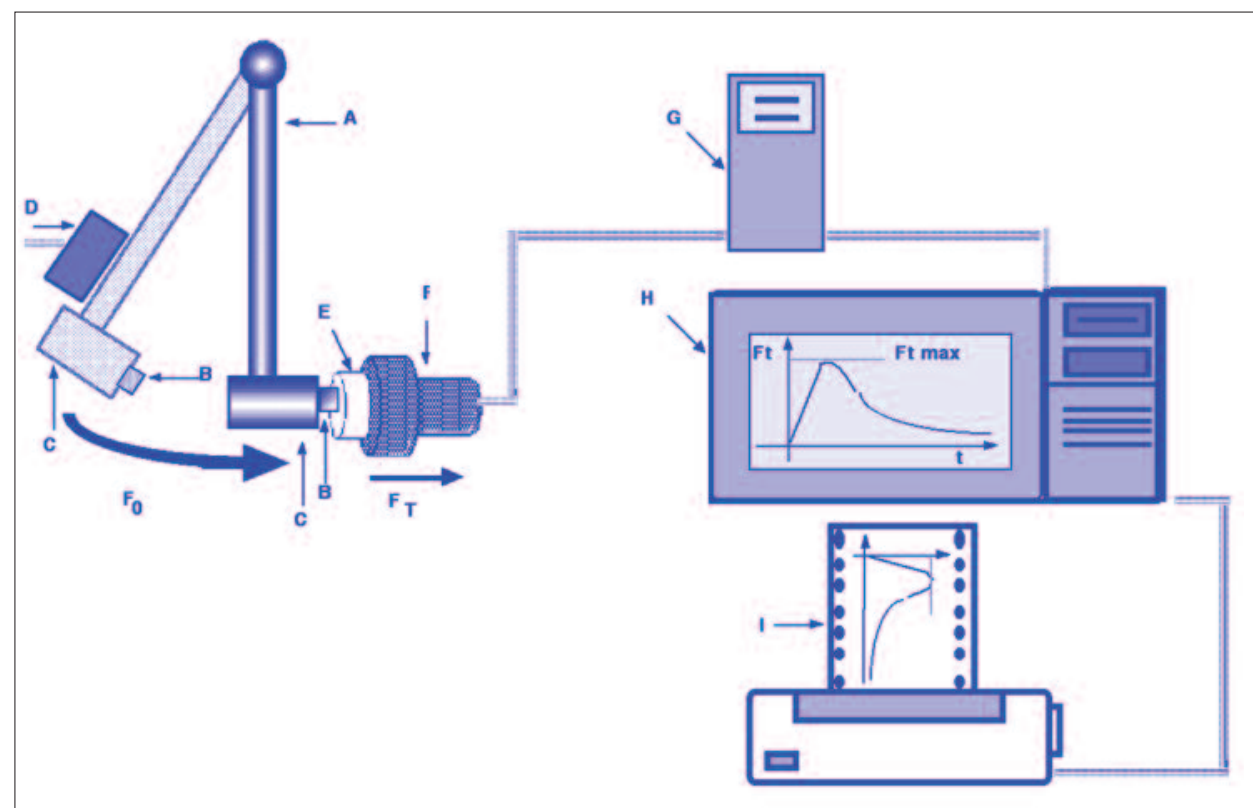

Fig. 2 Mesure de la capacité d'absorption des chocs des matériaux testés.

A : pendule, B : poinçon cylindrique, C : masselotte, D: électro-aimant, E : pastille,

F : capteur de force, G : conditionneur, : oscilloscope, I : traceur.

$\mathrm{Fo}=$ force d'impact Ft max du pendule = force maximale transmise au capteur.

$\mathrm{Ft}=$ force transmise au capteur. 
L'échantillon, conservé dans un bain thermostatique à $23^{\circ} \mathrm{C}$, est placé devant un capteur de force thermorégulé à $23^{\circ} \mathrm{C}$. Les variations des forces transmises au capteur sont ensuite transcrites sur un traceur en fonction du temps. Cette fonction $\mathrm{Ft}=\mathrm{f}(\mathrm{t})$ donne la valeur maximale de la force transmise au support ( $\mathrm{Ft} \max$ ) après absorption d'une partie de la force par le matériau testé. Un étalonnage (lancer à vide) est réalisé en début de mesure, il fournit la valeur Fo de référence. La force d'impact du pendule est fixée à $\mathrm{Fo}=3000 \mathrm{~N}$, c'est la force nécessaire à la rupture de la mandibule en choc direct [14].

Les 10 pastilles provenant d'un même échantillon sont ensuite successivement testées par un seul lancer. Pour chaque lancer, la valeur maximale de la force résiduelle transmise au capteur après absorption par l'échantillon (Ft max) est rapportée à celle du lancer à vide (Fo). Pour chacune des 10 pastilles provenant d'une même plaque, la valeur $\mathrm{F}=\mathrm{Ft}$ max/Fo est calculée. La moyenne des 10 valeurs est ensuite calculée pour chacun des 27 matériaux testés. Cette valeur (F) représente la quantité maximale de force transmise au support après absorption par le matériau. Elle est représentative de la contrainte maximale que subit le sup- port ostéo-muqueux ou dentaire lors d'un impact au cours d'une pratique sportive. Quand la valeur F augmente, c'est que la capacité d'absorption de choc du matériau de protection testé diminue.

L'influence de l'humidification de l'intrados de la protection dento-maxillaire sur la capacité d'absorption des chocs a été étudiée sur le matériau Q7 48-40 (échantillon 8). Un lancer a été effectué sur 10 pastilles de cet élastomère préalablement humidifié au niveau de l'intrados, puis un lancer a été effectué sur 10 autres pastilles du même échantillon à sec.

L'analyse statistique a été réalisée sur le logiciel Delta-Soft (Delta Consultants, Meylan, France) [15].

\section{Résultats}

Les matériaux qui présentent les plus grandes valeurs de dureté sont ceux qui absorbent moins bien le choc (fig. 3). Cette observation est confirmée par un calcul de régression linéaire simple qui montre que, pour ces 27 matériaux, il existe une liaison statistiquement significative entre la dureté et la valeur de $F(p<0,05)$ (tableau IV à VII). La liaison est

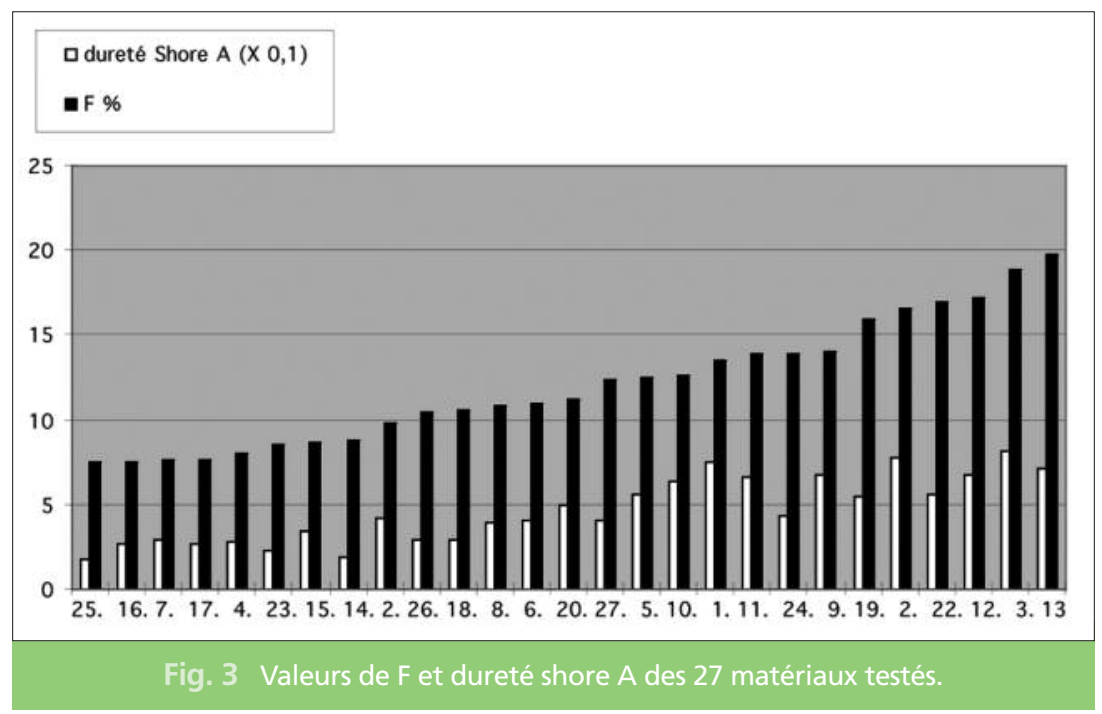


positive : quand la dureté augmente, le pourcentage maximal de force transmise au support (F) augmente également. Cependant, la relation n'est pas linéaire et l'écart à la linéarité augmente pour les valeurs extrêmes de dureté [15]. Ainsi, la dureté est inversement proportionnelle aux capacités d'absorption de choc d'un matériau donné. Ce critère significatif pour les matériaux homogènes l'est beaucoup moins pour les matériaux hétérogènes pour lesquels la dureté est un critère beaucoup moins significatif de la capacité d'absorption des forces de choc.

L'analyse statistique appliquée à l'ensemble des produits commercialisés (échantillons 1 à 3 ) et des élastomères de silicone bruts (échantillons de 4 à 9) montre que la force de choc est mieux absorbée par tous les élastomères de silicone, excepté le produit Q7 48-65 (échantillon 9). Parmi les élastomères bruts, les produits MDX4-4210 (échantillon 7) et RTV 71556 (échantillon 4) présentent les plus faibles valeurs de $\mathrm{F}$. Parmi les produits commercialisés, le Majorplast (échantillon 1) présente les plus faibles valeurs de F, alors que SR-Ivocap (échantillon 3) présente les valeurs les plus importantes.

L'application du test de Newman-Keuls sur les différents groupes constitués d'un élastomère brut et de tous les produits modifiés à partir de celui-ci permet d'évaluer l'effet des adjuvants sur les propriétés d'absorption des forces de choc des élastomères bruts [15].

\section{$>$ Effets de l'adjonction d'huile}

\section{(tableau IV)}

D'une manière générale, l'adjonction d'huile aux élastomères bruts améliore significativement l'absorption des forces de choc et diminue corrélativement leur dureté, exceptée pour le produit MDX-4-4210 (échantillon 7) dont les valeurs de $\mathrm{F}$ ne sont pas significativement modifiées par l'adjonction de $20 \%$ ou $10 \%$ d'huile de silicone réactive (échantillons 16 et 17).

\section{$>$ Effets de l'incorporation de tissu de verre stratifié (tableau V)}

L'incorporation de tissu de fibres de verre stratifié augmente les valeurs de F. Par conséquent,

\begin{tabular}{|c|c|c|c|c|c|c|c|c|c|c|c|c|c|c|c|}
\hline Echantillons & 4 & 5 & 6 & 7 & 8 & 9 & 10 & 11 & 14 & 15 & 16 & 17 & 21 & 23 & 25 \\
\hline Valeurs de $F(\%)$ & 8 & 12,51 & 11,01 & 7,67 & 10,81 & 14,06 & 12,69 & 13,92 & 8,75 & 8,61 & 7,48 & 7,69 & 9,84 & 8,58 & 7,47 \\
\hline Erreur standard & $\pm 0,1$ & $\pm 0,15$ & $\pm 0,1$ & $\pm 0,11$ & $\pm 0,2$ & $\pm 0,08$ & $\pm 0,09$ & $\pm 0,11$ & $\pm 0,09$ & $\pm 0,13$ & $\pm 0,08$ & $\pm 0,07$ & $\pm 0,13$ & $\pm 0,31$ & $\pm 0,1$ \\
\hline Dureté & 28 & 56 & 40,83 & 28,75 & 40 & 67 & 64,08 & 66,58 & 19 & 35 & 26,33 & 27,33 & 41,67 & 23 & 17,92 \\
\hline Erreur standard & $\pm 0,13$ & $\pm 0,19$ & $\pm 0,12$ & $\pm 0,14$ & $\pm 0,26$ & $\pm 0,1$ & $\pm 0,12$ & $\pm 0,14$ & $\pm 0,11$ & $\pm 0,17$ & $\pm 0,1$ & $\pm 0,09$ & $\pm 0,17$ & $\pm 0,22$ & $\pm 0,13$ \\
\hline
\end{tabular}

\begin{tabular}{|c|c|c|c|c|c|c|c|c|c|c|c|}
\hline Echantillons & 4 & 5 & 6 & 7 & 9 & 12 & 13 & 18 & 22 & 24 & 25 \\
\hline Valeurs de $F(\%)$ & 8 & 12,51 & 11,01 & 7,67 & 14,06 & 17,25 & 19,71 & 10,56 & 16,96 & 13,92 & 10,46 \\
\hline Erreur standard & $\pm 0,1$ & $\pm 0,15$ & $\pm 0,1$ & $\pm 0,11$ & $\pm 0,08$ & $\pm 0,35$ & $\pm 0,46$ & $\pm 0,18$ & $\pm 0,31$ & $\pm 0,11$ & $\pm 0,17$ \\
\hline Dureté & 40,83 & 56 & 40,83 & 28,75 & 67 & 67,5 & 71 & 29,67 & 55,67 & 43 & 29,17 \\
\hline Erreur standard & $\pm 0,13$ & $\pm 0,19$ & $\pm 0,12$ & $\pm 0,14$ & $\pm 0,1$ & $\pm 0,46$ & $\pm 0,59$ & $\pm 0,23$ & $\pm 0,4$ & $\pm 0,15$ & $\pm 0,22$ \\
\hline
\end{tabular}


elle diminue les capacités d'absorption des chocs des élastomères de silicone. Les valeurs de dureté des élastomères bruts sont peu modifiées par l'incorporation de tissus de verre stratifiés.

\section{$>$ Effets de l'incorporation de fibres de verre fragmentées (tableau VI)}

L'incorporation de fibres de verre fragmentées associées à $20 \%$ d'huile diminue les capacités $d$ 'amortissement des élastomères de silicone excepté pour les produits RTV 70-147 dont les valeurs de $\mathrm{F}$ et de dureté sont diminuées.

\section{> Fatigue des matériaux}

II n'existe pas de fatigue significative après plusieurs impacts de $3000 \mathrm{~N}$.

La capacité d'absorption de choc d'un élastomère de silicone n'est pas altérée par des chocs répétés. En effet, $\mathrm{F}=364 \mathrm{~N} \pm 3,1$ pour 10 lancers consécutifs sur un échantillon cylindrique de RTV $70-148$ et $F=320,4 \pm 8$ pour 10 lancers consécutifs sur un échantillon cylindrique de Q7 48-40.

\section{> Humidification du support}

La présence d'eau entre l'intrados des échantillons et le réceptacle du capteur modifie significativement l'absorption des chocs. Dix lancers successifs sur un échantillon d'élastomère de silicone mouillé Q7 48-40 donne une force transmise moyenne de 8,42 et une force transmise moyenne sur l'échantillon identique mais à sec de 10,69 ; soit une diminution de $21,33 \%$ de la force transmise du fait de la présence d'eau entre l'échantillon et le support.

À $23{ }^{\circ} \mathrm{C}, \mathrm{F}=256 \mathrm{~N} \pm 8$ pour 10 lancers sur 10 échantillons de Q7 48-40 mouillés (soit 8,4 \% de la force d'impact) et $\mathrm{F}=320,8 \mathrm{~N} \pm 14,8$ pour 10 lancers sur 10 échantillons de Q7 48-40 secs (soit $10,69 \%$ de la force d'impact).

\section{Discussion}

La valeur $\mathrm{F}$ est représentative du pourcentage maximal de force résiduelle transmise au support, c'est-à-dire aux tissus buccaux, au cours d'un choc. L'utilisation de cette valeur calculée a été préférée à la valeur directe de la force maximale transmise au support (Ft max), en raison d'une légère dérive du banc de simulation due aux vibrations répétées au cours des tests (l'ensemble de l'expérimentation a compté 450 lancers, mené par séries de 10 sur un délai de 1 mois). Deux séries de 10 lancers à vide ont été effectuées en début et en fin d'expérimentation. Leur comparaison par l'utilisation du test $\mathrm{T}$ de Student montre que la répétition des vibrations tend à augmenter la valeur de Fo au cours du temps (lancer à vide en début d'expérimentation $\mathrm{Fo}=3004 \mathrm{~N} \pm 35$ et lancer à vide en fin d'expérimentation Fo $=3032 \mathrm{~N} \pm 17$;

\begin{tabular}{|c|c|c|c|c|c|c|}
\hline Tableau & \multicolumn{6}{|c|}{$\begin{array}{l}\text { Valeurs de F et de dureté des élastomères de sili- } \\
\text { cone bruts et modifiés par adjonction de fibres } \\
\text { de verre fragmentées. (Les différents tons de gris } \\
\text { regroupent les élastomères originaux et leurs } \\
\text { produits modifiés). }\end{array}$} \\
\hline Echantillons & 4 & 5 & 7 & 19 & 22 & 25 \\
\hline Valeurs de $F(\%)$ & 8 & 12,51 & 7,67 & 15,82 & 11,27 & 12,33 \\
\hline Erreur standard & $\pm 0,1$ & $\pm 0,15$ & $\pm 0,11$ & $\pm 0,36$ & $\pm 0,4$ & $\pm 0,41$ \\
\hline Dureté & 28 & 56 & 28,75 & 55 & 50,33 & 41 \\
\hline Erreur standard & $\pm 0,13$ & $\pm 0,19$ & $\pm 0,14$ & $\pm 0,06$ & $\pm 0,52$ & $\pm 0,53$ \\
\hline
\end{tabular}

\begin{tabular}{|c|c|c|c|}
\hline \multicolumn{4}{|c|}{$\begin{array}{l}\text { Tableau VII Valeurs de F et de dureté des } \\
\text { produits commercialisés. }\end{array}$} \\
\hline Echantillons & 1 & 2 & 3 \\
\hline Valeurs de F (\%) & 13,54 & 16,62 & 18,86 \\
\hline Erreur standard & $\pm 0,01$ & $\pm 0,05$ & $\pm 0,09$ \\
\hline Dureté & 75 & 78 & 82 \\
\hline Erreur standard & $\pm 0,02$ & $\pm 0,06$ & $\pm 0,12$ \\
\hline
\end{tabular}


$p<0,05, d d l=18$ ). Cette observation justifie l'étalonnage pour chaque lancer et l'utilisation de la valeur relative $\mathrm{F}=\mathrm{Ft}$ max/Fo pour chaque impact.

Les mesures de $\mathrm{F}$ et de dureté ont été réalisées individuellement sur des échantillons d'une même plaque portée et maintenue à $23{ }^{\circ} \mathrm{C}$ pendant toute la durée du test afin d'évaluer leur capacité à la température buccale moyenne [9]. Ainsi chaque échantillon ne subit qu'un seul impact, afin de pallier d'éventuelles transformations irréversibles du matériau par des impacts successifs. Cependant, des séries de mesures de $\mathrm{F}$ répétées sur un même échantillon de silicone montrent que la capacité d'absorption de choc d'un élastomère de silicone n'est pas altérée par des chocs répétés $(F=364 N \pm 3,1$, pour 10 lancers consécutifs sur un échantillon cylindrique de RTV 70-148 et $F=320,4 \pm 8$ pour 10 lancers consécutifs sur un échantillon de Q7 48-40).

Il est donc inutile de conseiller le remplacement des protections dento-maxillaires en élastomère de silicone à la suite d'un traumatisme ou d'un impact violent, sauf si celle-ci est macroscopiquement délabrée (déchirement, fissure, etc.).

Tous les élastomères de silicone évalués dans notre travail répondent d'après leurs fournisseurs aux normes de biocompatibilité, mais certains seulement répondent partiellement ou complètement au cahier des charges des protections dento-maxillaires, établi par d'autres auteurs $[2,4,7,8,12,17]$. Les critères coût et rétention, mentionnés par certains auteurs ne sont pas repris dans cette étude. En effet, les 27 matériaux testés demandent une mise en œuvre au laboratoire sur les moulages du patient, ils sont par conséquent considérés comme onéreux. Par ailleurs, nous n'avons réalisé aucune mesure de rétention, mais l'inter- prétation que l'on peut faire des caractéristiques de dureté et d'adaptation de ce matériau peut fournir des informations. Ainsi, si l'on considère que la rétention augmente avec la dureté du matériau, les protections dentomaxillaires réalisées en élastomère de silicone peuvent être considérées comme moyennement rétentives. En revanche, si l'on considère que la rétention est fonction de la fidélité d'adaptation aux tissus bucco-dentaires du sportif, la rétention des protections dentomaxillaires réalisées en élastomère de silicone sera considérée comme suffisante. L'évaluation comparative d'élastomère de silicone (dureté shore A 50) utilisé pour la réalisation de protections dento-maxillaires chez des joueurs de rugby met en évidence une stabilité moindre par rapport aux mêmes protections dentomaxillaires réalisées en methylmétacrylate (dureté shore A 80) [18]. Cependant, la stabilité et la rétention augmentant avec la dureté des protections dento-maxillaires, il est probable qu'à dureté égale les protections dentomaxillaires en élastomère de silicone présentent une rétention proche de celle des protections dento-maxillaires en méthylmétacrylate. Les élastomères de silicone évalués présentant des capacités d'absorption de chocs très supérieures aux produits habituellement utilisés pour la confection des protections dento-maxillaires, nous pouvons donc préconiser l'utilisation de ces élastomères de silicone pour leur réalisation.

Parmi cette catégorie d'élastomère, le produit MDX-4-4210 brut (échantillon 7), ses produits modifiés par l'addition d'huile de silicone (échantillons 16 et 17) et le RTV 71556 brut (échantillon 4) répondent à tous ces critères. En revanche, le produit RTV 71556 présente une certaine fragilité à l'entaille et ne repolymérise pas sur lui-même, ce qui interdit toute transformation ou réparation. 
En ce qui concerne la réalisation de protections dento-maxillaires composites, I'introduction de fibres de verre n'améliore pas l'absorption des forces de choc. Mais, lorsque les chocs sont violents et rapides (sports de combat), elle peut être recherchée localement dans le but d'éviter le déchirement du matériau soumis au contact des surfaces coupantes, par exemple au niveau des bords incisifs. L'amélioration des capacités d'absorption des forces de chocs étant liée à la diminution de la dureté, les protections dentomaxillaires peuvent s'en trouver fragilisées. II peut donc être utile d'augmenter localement la résistance de l'élastomère de silicone par incorporation de tissu de fibres de verre stratifié ou de réaliser une infrastructure en élastomère de silicone de dureté élevée recouverte d'une superstructure en élastomère de silicone de faible dureté chimiquement liée à la précédente. L'intérêt de ce concept est évident par rapport aux infrastructures métalliques parfois préconisées pour assurer la répartition d'impacts ponctuels sur l'ensemble de l'arcade et conférer à la protection dento-maxillaire une rigidité accrue et une rétention suffisante [16]. En effet celle-ci présente l'inconvénient de se désolidariser de l'élastomère sous la contrainte, donc de très mal répartir le choc, voire de perforer la superstructure élastomère et d'agresser les tissus buccaux. La liaison chimique entre les tissus de verre stratifiés et les différentes couches d'élastomère de dureté différente assure une parfaite transmission des contraintes et interdit la rupture de l'interface renfort/matrice (délaminage verre/élastomère). Les échantillons d'élastomères réalisés par incorporation de tissu de fibres de verre, bien que chimiquement liés aux stratifiés, sont particulièrement hétérogènes (fig. 4) et la situation du tissu de fibres de verre par rapport à l'impact n'est pas sans effet sur les performances. Nous I'avons évalué de la manière sui- vante : les échantillons 12 et 26 ont fait l'objet d'une nouvelle série de mesures de $F$, en plaçant la face stratifiée des échantillons du côté de I'impact, contrairement aux mesures réalisées précédemment. Un test $U$ de Mann et Wittney, appliqué sur les deux séries de mesures, montrent que les plus faibles valeurs de $\mathrm{F}$ sont obtenues lorsque le tissu de verre stratifié est placé à distance du point d'impact (fig. 5). Par conséquent, lorsque des tissus de verre sont utilisés pour renforcer des élastomères de silicone de faible dureté, ils doivent êtres déposés de préférence près de l'intrados de la protection, sans s'étendre au-delà des limites des tissus durs, la dureté et donc le pourcentage de force transmise étant augmenté par l'incorporation de

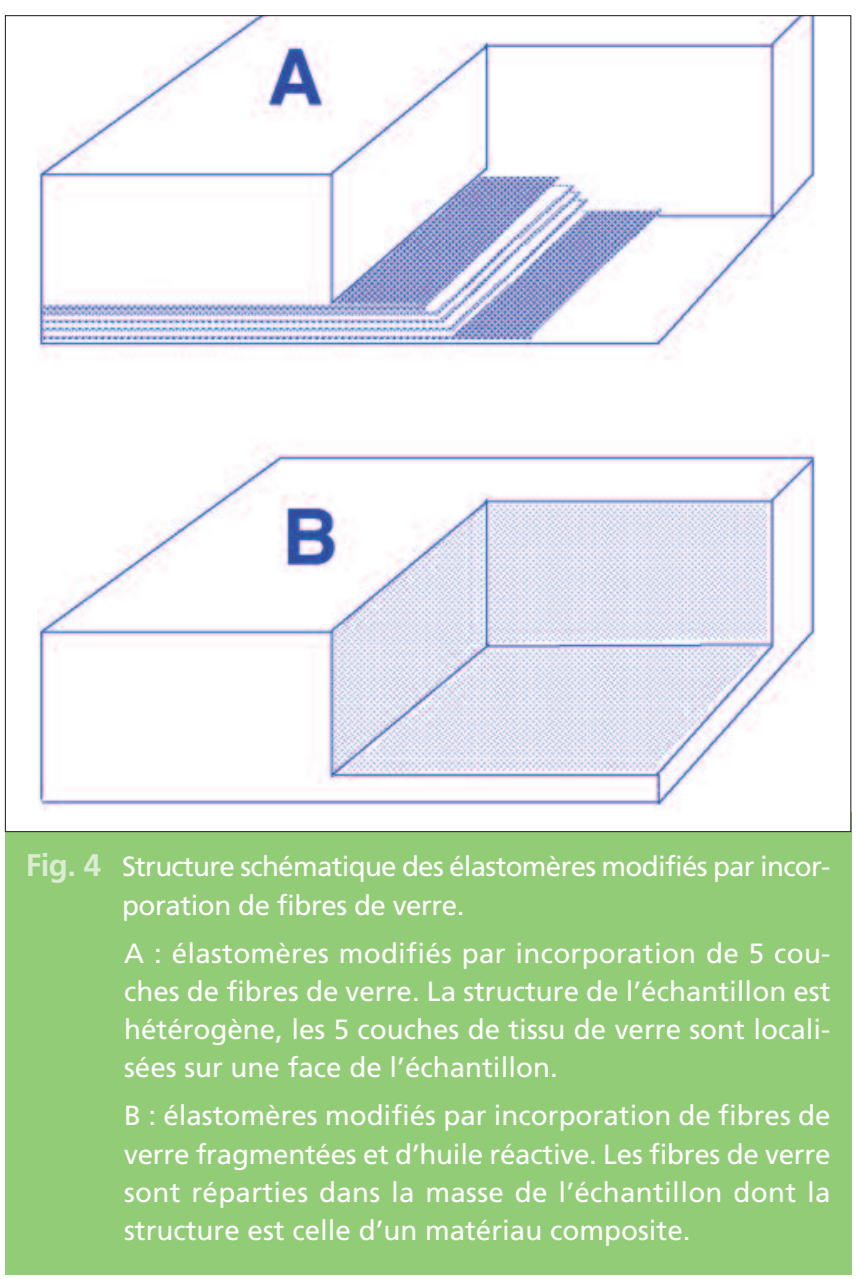



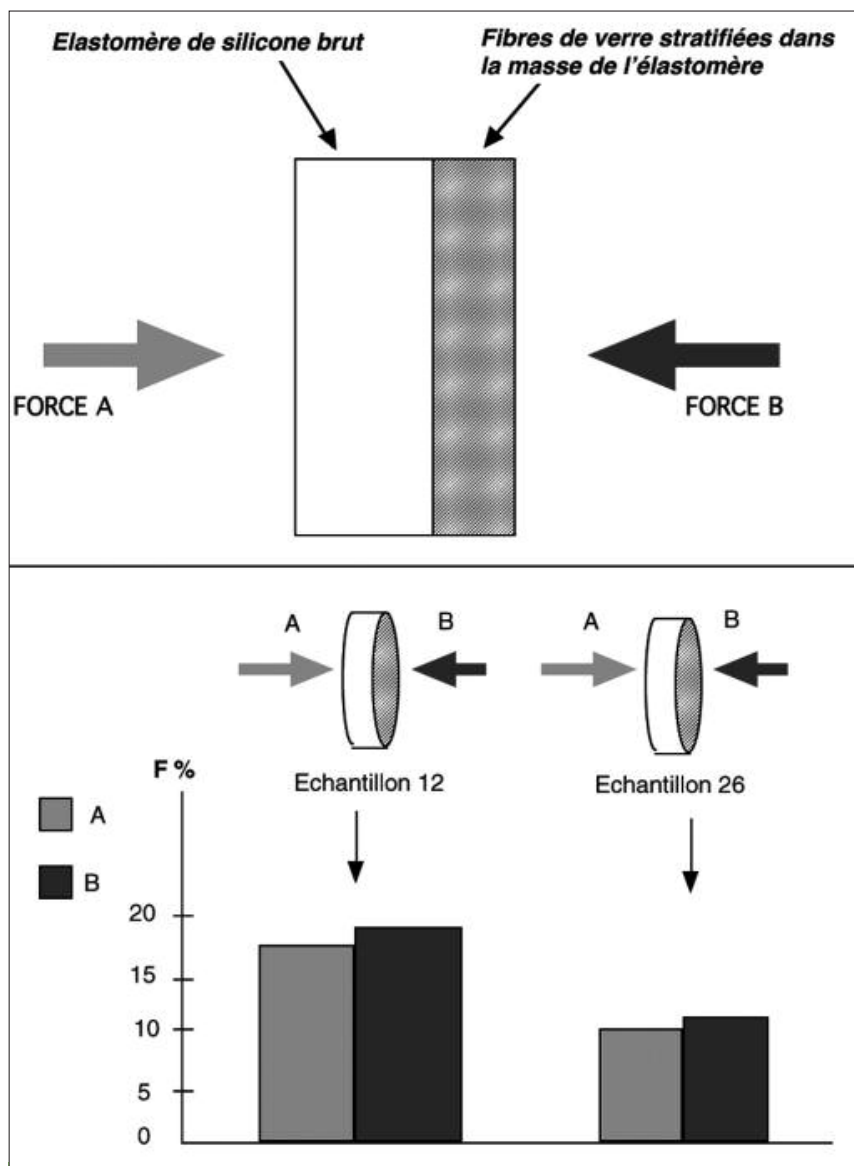

Fig. 5 Variations des valeurs de F en fonction de la position de l'échantillon par rapport à l'impact pour les échantillons contenant des fibres de verre stratifiées sur une face. Les valeurs de F sont significativement augmentées quand les fibres de verre stratifiées sont placées du côté de l'impact pour les échantillons 12 et 26. ( $p<0,05$, test de Mann et Whitney). fibres, les risques de lésions des tissus mous seraient alors majorés.

La présence d'eau entre l'intrados des protections dento-maxillaires représentée en bouche par la salive (990 mL d'eau par litre de salive) [19] améliore significativement l'absorption des chocs.

Bien que ce phénomène ne soit pas élucidé, nous proposons deux hypothèses.

Le film liquidien prisonnier entre l'intrados et les tissus buccaux en se déformant sous la pression de l'impact absorbe une partie de l'énergie.

Le film liquidien constitue un plan de glissement entre l'intrados et les tissus buccaux. II permet ou facilite les déformations perpendiculaires à la force d'impact qui ne sont pas possibles lorsque l'intrados de la protection dentomaxillaire adhère aux tissus qu'elle protège. Ces déformations absorbent alors une partie de la force d'impact.

Les deux hypothèses bien que non démontrées sont vraisemblablement concomitantes et contribuent ensemble à une amélioration notable des performances $(-21,33 \%$ de force transmise).

Nous pouvons donc conseiller I'humidification préalable de l'intrados des protections dentomaxillaires avant leur insertion.

\section{Évaluation biologique}

Les résultats de la première partie mettent en évidence la supériorité des élastomères de silicone dans la capacité d'absorption des chocs par rapport aux matériaux habituellement utilisés pour la confection des protections dentomaxillaires.

Avant de proposer les élastomères de silicone en alternative aux produits habituels, il est nécessaire d'évaluer et de comparer leur biocompatibilité, paramètre prépondérant pour des matériaux destinés à séjourner au contact des tissus buccaux.

La viabilité cellulaire a été étudiée par le test colorimétrique au MTT. La prolifération cellulaire a été estimée par cytométrie de flux. Enfin, l'examen en microscopie électronique à 
balayage (MEB) a permis d'évaluer les variations morphologiques cellulaires provoquées par les produits testés.

\section{Matériel et méthode}

\section{$>$ Choix des matériaux}

Les matériaux retenus pour notre étude sont les trois élastomères habituellement utilisés pour la confection des protections dento-maxillaires : SR-Ivocap, Plastulène, Major-plast et trois élastomères de silicone choisis parmi ceux évalués dans la première partie de notre étude, et sélectionnés pour leur performance en absorption des chocs : le RTV 71556, le Q7 48-40 et le MDX4-4210.

Les trois élastomères préconisés pour la réalisation des PDM ont été fabriqués selon les recommandations des fournisseurs.

Les trois mélanges maîtres d'élastomères de silicone ont été modifiés par adjonction, en proportion variable, d'huiles réactives, respectivement : $20 \%$ H47V1000 (Rhodia) pour le RTV 71556, $10 \%$ H47V1000 (Rhodia) + $10 \%$ d'hexaméthyl disiloxane : DC200-0,65cs (Dow-Corning) pour le Q7 $48-40$ et $20 \%$ de DC200-0,65cs (Dow-Corning) pour le MDX-4-4210.

Le témoin positif choisi pour cette étude est un élastomère de polyuréthane industriel : Uréol (XB5073 + 6414B, dureté de 35-40 shore A), issu de la réaction d'un isocyanate sur un polyol comme agent de réticulation [20,21].

Le polystyrène des boîtes de culture traité pour leur utilisation en biologie cellulaire constitue le témoin négatif de la cytotoxicité.

Pour chacun de ces échantillons, un numéro a été attribué. Le tableau VIII regroupe les différents échantillons étudiés et leurs caractéristiques.

\section{Préparation et traitement}

Les matériaux commercialisés ont été réalisés en plaque de $2 \mathrm{~mm}$ d'épaisseur, polymérisés à chaud sous pression selon les recommandations du fabricant dans des moules métalliques polis miroirs.

Les élastomères de silicone ont été préparés en mélange maître auquel de I'huile réactive a été ajoutée, puis catalysés selon les recommandations du fabricant et coulés dans des moules parallélépipédiques polis miroirs de

\begin{tabular}{|c|c|c|c|}
\hline Échantillon $\mathrm{N}^{\circ}$ & Nom commercial & Code de composition & Fabricant \\
\hline 1 & $\begin{array}{l}\text { Medical Dow Corning, } \\
\text { MDX } 4.4210\end{array}$ & polyvinylsiloxane $+20 \%$ DC Fluide & $\begin{array}{l}\text { Dow-Corning Corporation } \\
\text { (Midland, Mich) }\end{array}$ \\
\hline II & $\begin{array}{l}\text { Silbione, } \\
\text { RTV } 71556\end{array}$ & polyvinylsiloxane $+20 \%$ DC Fluide & $\begin{array}{c}\text { Rhodia } \\
\text { (Neuilly/Seine, France) }\end{array}$ \\
\hline III & $\begin{array}{l}\text { Medical Dow Corning, } \\
\text { Q7 } 4840\end{array}$ & $\begin{array}{c}\text { polyvinylsiloxane }+10 \% \text { DC Fluide } \\
+10 \% \text { RP Fluide }\end{array}$ & $\begin{array}{l}\text { Dow-Corning Corporation } \\
\text { (Midland, Mich) }\end{array}$ \\
\hline IV & SR Ivocap & styrol polyolefin methyl metacrylate & Ivoclar (St-Jorioz, France) \\
\hline V & Plastulene & poly vinyl acétate polyéthylène & Dental Polymer Italina (Biella, Italie) \\
\hline VI & Majorplast & poly vinyl acétate polyéthylène & Major (Acigné, France) \\
\hline VII & Ureol XB5073 + 6414B & polyuréthane & $\begin{array}{c}\text { Ciba-Geigy } \\
\text { (Rueil-Malmaison, France) }\end{array}$ \\
\hline VIII & Plastique de culture & polystyrène de culture & $\begin{array}{c}\text { Nunc } \\
\text { (/Poly labo, Strasbourg, France) }\end{array}$ \\
\hline
\end{tabular}


$130 \times 130 \times 2 \mathrm{~mm}$ en polyméthyl métacrylate (Plexiglas).

Ils ont ensuite été réticulés à $70^{\circ} \mathrm{C}$ pendant 5 heures pour les échantillons I et III et à température ambiante $\left(20^{\circ} \mathrm{C}\right)$ pendant 24 heures pour l'échantillon II.

Une fois démoulées, les plaques d'élastomère de silicone ont subi un recuit de 4 heures à $120^{\circ} \mathrm{C}$ afin d'assurer leur complète réticulation.

Pour cette étude, tous les matériaux ont dû être découpés à l'emporte-pièce afin d'obtenir des échantillons d'un diamètre de $15 \mathrm{~mm}$.

Le traitement choisi pour ces matériaux a été un lavage au savon de Marseille suivi d'un rinçage abondant à l'eau courante puis à l'eau distillée stérile.

Les échantillons sont conservés dans des flacons stériles contenant un bain d'antibiotiques et des antifongiques : tétracycline à $10 \mathrm{mg} / \mathrm{L}$ et de l'amphotéricine $B$ à $1 \mu \mathrm{g} / \mathrm{mL}$ à une température de $4^{\circ} \mathrm{C}$ jusqu'au moment de la manipulation.

Au moment de l'expérimentation, les échantillons sont placés au fond des macropuits des boîtes de culture. L'espace minime existant entre les parois du puits et l'échantillon est comblé par une solution d'agar à $1 \%$, préalablement mise en place dont la non-cytotoxicité a été démontrée auparavant.

Après chaque expérimentation, les échantillons sont placés dans de la trypsine $(0,1 \%)$ pour éliminer tous les éléments protéiques pouvant se trouver en surface puis sont rincés à l'eau distillée stérile.

\section{Culture cellulaire}

Les cellules KB (ATCC CCL-7) sont issues d'une lignée cellulaire transformée d'un cancer épidermoïde buccal humain. Elles sont cultivées dans un milieu RPMI1640 complémenté par $10 \%$ de sérum de veau fœtal, 2 mM de L-glu- tamine et des antibiotiques (pénicilline$100 \mathrm{UI} / \mathrm{mL}$, streptomycine $100 \mu \mathrm{g} / \mathrm{mL}$ ).

Deux repiquages hebdomadaires assurent la croissance exponentielle de cette lignée. Le décollement des cellules a été réalisé par l'action du mélange trypsine $(0,05 \%)$-EDTA $(0,02 \%)$.

L'ensemencement s'est effectué après comptage des cellules sur hématimètre de Thoma. Le dénombrement, accompagné d'un test d'exclusion au bleu Trypan au moment de la mise en culture, a permis d'évaluer la viabilité cellulaire. Les cultures ont été maintenues dans un incubateur à $\mathrm{CO}_{2}(5 \%)$, à température $\left(37^{\circ} \mathrm{C}\right)$ et humidité (> $90 \%$ ) constantes.

Régulièrement, les cellules ont été traitées contre une éventuelle contamination mycoplasmique ( 10 jours de RMA +10 jours de tylosine).

\section{Moyens d'investigation}

Chaque test a été réalisé trois fois de façon indépendante et à deux temps de contact différents. L'ensemencement a été de $2.10^{5}$ cellules par macropuits pour les tests à 24 heures et de $4.10^{4}$ cellules pour ceux à 72 heures de façon à obtenir une culture non confluente à 24 heures et 72 heures.

En effet, la détermination d'un nombre initial optimal de cellules est nécessaire afin d'éviter la confluence mais également d'aboutir à un nombre de KB suffisamment important pour effectuer les différentes analyses.

\section{$>$ Test au MTT) [22]}

Le protocole appliqué est celui de IGNATIUS [23] comportant quelques modifications.

Le MTT (bromure de diméthylthiazoldiphényltétrazolium) est ajouté au milieu de culture à une concentration finale de $1 \mathrm{mg} / \mathrm{mL}$, suivi de 
4 heures d'incubation permettant à ce colorant jaune, de se transformer par les déshydrogénases mitochondriales en cristaux de formazan de couleur bleu. Le surnageant est remplacé par $500 \mu \mathrm{L}$ de DMSO. Une agitation de 10 minutes assure la dissolution complète des cristaux de formazan. Après prélèvement de deux aliquots de $100 \mu \mathrm{L}$ dans chaque puits, la densité optique à $550 \mathrm{~nm}$ est mesurée grâce à un lecteur ELISA (DYNATECK MR 5000) évaluant ainsi la viabilité cellulaire à $570 \mathrm{~nm}[24,25]$.

\section{> Cytométrie en flux}

Les cellules en culture sont incubées 1 heure avec le Bromo-Uracyl-désoxyribose : BUdR, nucléotide modifié qui permet la quantification des cellules en phase $S$, marqueur de la prolifération [26], à une concentration finale de $10 \mu \mathrm{m}$ $\left(37^{\circ} \mathrm{C}\right)$. Elles sont ensuite rincées avec du PBS (Phosphate Buffer Saline), deux fois, puis décollées avec le mélange trypsine-EDTA. Après centrifugation, le culot est repris avec $500 \mu \mathrm{L}$ d'éthanol $70^{\circ}\left(-20^{\circ} \mathrm{C}\right)$, vortexé et incubé 1 heure sur un lit de glace. La suite des manipulations s'effectue à température ambiante. L'alcool est éliminé, l'ADN est dénaturé en condition acide ( $\mathrm{HCl} 2 \mathrm{~N} ; 30$ minutes). Après neutralisation grâce au tampon borate $(\mathrm{pH} 8$; $0,1 \mathrm{M})$, les cellules sont perforées $(15 \mathrm{~min}$ ) à I'aide d'une solution de PBS à 0,5\% Tween 20, puis saturées (15 $\mathrm{min}$ ) dans le PBS additionné de $1 \%$ de BSA. L'incubation avec I'anticorps murin (15 min) anti-BUdR est suivie de deux lavages au PBT; l'immunoglobuline anti-souris marquée à la FITC (Fluorescéine IsoThio Cyanate) étant appliquée dans les mêmes conditions. Quinze minutes avant l'analyse au cytomètre, l'iodure de propidium $(10 \mu \mathrm{m} / \mathrm{mL})$ est mis en contact des cellules. À I'aide de ce fluorochrome, deux sous-populations vont être distinguées : les cellules en phases G0G1 contenant une quantité $2 C$ d'ADN et les cellules en G2M correspondant aux stades G2M du cycle cellulaire, $C$ étant défini comme la quantité d'ADN d'un génome haploïde.

Les témoins réalisés simultanément sont :

- l'omission de l'anticorps primaire ;

- l'anticorps primaire spécifique, de même isotype que I'anti-BUdR.

L'analyse des cellules s'effectue grâce au FACsan et au logiciel LYSIS II.

Dans un premier temps, les cellules sont sélectionnées selon des critères morphologiques (paramètres Fas et Ras) qui permettent d'exclure les débris cellulaires et les agrégats cellulaires. Seules seront analysées, ultérieurement, les cellules isolées et intactes.

\section{Microscopie électronique à balayage}

Le surnageant de culture est délicatement éliminé sans altérer la monocouche cellulaire. Après un lavage au PBS additionné de calcium et de magnésium, les cellules sont fixées dans une solution de glutaraldéhyde à $2,5 \%$ pendant deux heures à température ambiante. Après deux rinçages au PBS, les échantillons sont déshydratés dans des bains d'éthanol de degré croissant. Après passage au point critique, la métallisation est réalisée par un mélange or-palladium. Les échantillons sont ensuite observés au MEB (JEOL 6400).

Pour chaque essai, cinq observations ont été effectuées pour chaque matériau à deux grandissements différents (x $300 ;$ x 3000).

\section{$>$ Analyse statistique des résultats}

Le logiciel utilisé est le StatView ${ }^{\mathrm{TM}}$. L'analyse de variance (ANOVA) avec mesures répétées a permis de comparer les différentes moyennes.

Lorsque la valeur $F$ est significative $(p>0,05)$, un test de Fisher est réalisé pour comparer les moyennes. 


\section{Résultats}

\section{> Test de viabilité}

Pour chaque essai, le bruit de fond a été mesuré :

- sur polystyrène des boîtes de culture (milieu de culture sans cellule), il est de 0,15 $\pm 0,01$;

- sur matériau (matériau + agarose + milieu de culture), il s'élève à $0,162 \pm 0,02$.

Ces chiffres ont donc été retranchés, systématiquement des DO, afin d'obtenir une valeur nette.

Le pourcentage de viabilité a été calculé en fonction du polystyrène de culture (échantillon VIII). Cette référence est fixée à $100 \%$.

Globalement, les trois matériaux commercialisés pour la fabrication des PDM et les trois élastomères de silicone conduisent respectivement à une viabilité de $78,5 \%( \pm 10,6)$ et $86,8 \%$ $( \pm 6,4)$.

Le plus faible résultat enregistré $(62,9 \%)$ correspond au substrat IV (SR-Ivocap). Le polyuréthane, témoin de l'expérimentation, se situe à $36,8 \%$. La figure 6 représente les moyennes et

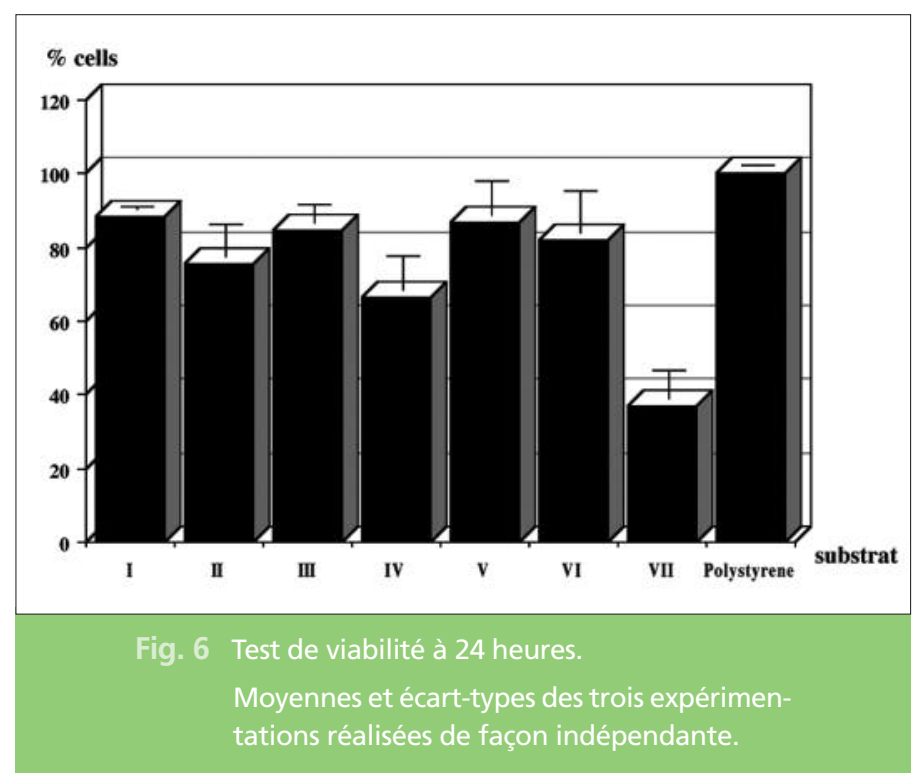

les écarts-types des trois expérimentations réalisées de façon indépendante.

On remarque une différence significative au seuil de $5 \%$ entre l'ensemble des échantillons évalués et le polyuréthane (témoin positif de la cytotoxicité). Seul le matériau I (MDX-4-4210) conduit à des taux de viabilité comparable à celui du "polystyrène " de culture. Le SR-Ivocap (échantillon IV) présente une toxicité significative par rapport aux autres échantillons, excepté le II (RTV 71556).

Après trois jours de culture, on assiste à une diminution importante de la viabilité cellulaire. En effet, les chiffres obtenus représentent 40 à $60 \%$ de ceux du témoin négatif de toxicité. Le matériau IV, à nouveau, conduit au résultat le plus bas (38,2 \% de viabilité). Le polyuréthane (témoin positif) se situe à $28,4 \%$. La figure 7 représente les moyennes et écart-types obtenus après trois jours de culture.

L'analyse de la variance atteste de la supériorité en termes de viabilité du polystyrène de culture. On enregistre des valeurs significativement plus basses pour les matériaux IV et VII par rapport à l'ensemble des échantillons éva-

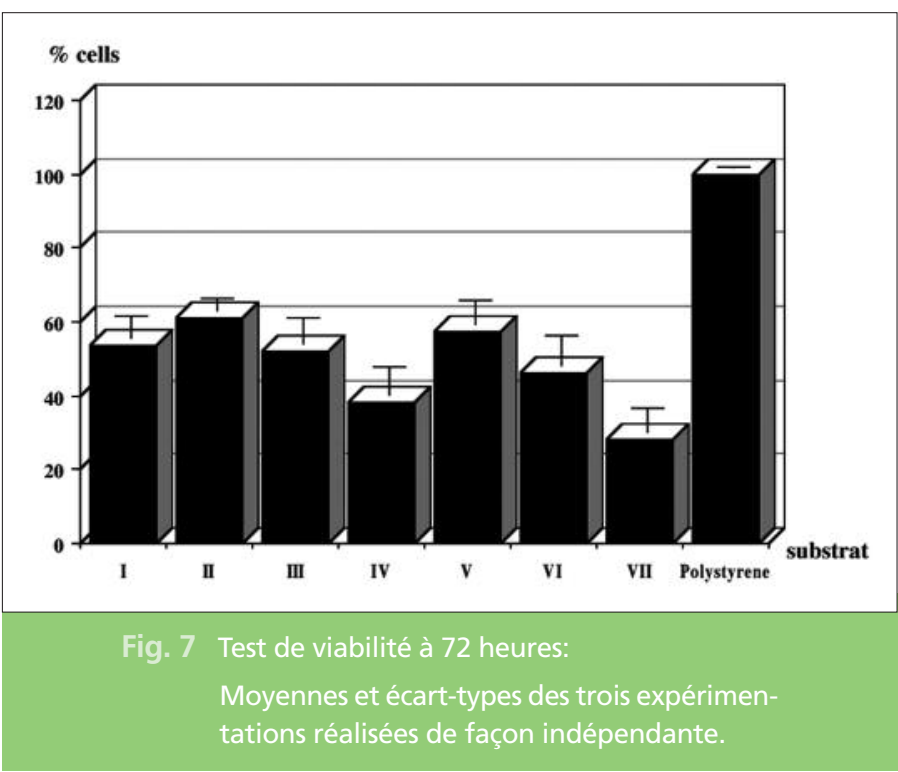


lués. De plus, il n'existe plus, comme précédemment, de différence significative entre les résultats obtenus avec ces deux matériaux.

\section{$>$ Cytométrie en flux}

Les résultats obtenus par cytométrie de flux à 24 heures et représentés dans la figure 8 montrent que, sur le polystyrène de culture, le nombre de cellules en phase Go-G1 est de $43,9 \pm 2,7 \%$, en phase $S$ de $22,9 \pm 5,9 \%$ et enfin en phase G2M de $13 \pm 3 \%$. En ce qui concerne le matériau I, le cycle cellulaire est sensiblement équivalent.

Pour les matériaux III, IV, VI et VII, on assiste à une accumulation des cellules en phase G0G1 (63 à $53 \%$ ) concomitante à une diminution des cellules en phase duplicative (28 à $35 \%$ ).

Le matériau VII présente le plus fort taux de cellules en phase G0G1 $(63,1 \%)$ et le plus faible pourcentage en phase $S(28,5 \%)$. La phase G2M pour ces quatre matériaux est sensiblement égale.

Les matériaux II et V sont caractérisés par un pourcentage de cellules en phase $S$ très important ( $p>0,05$ par rapport aux autres maté-

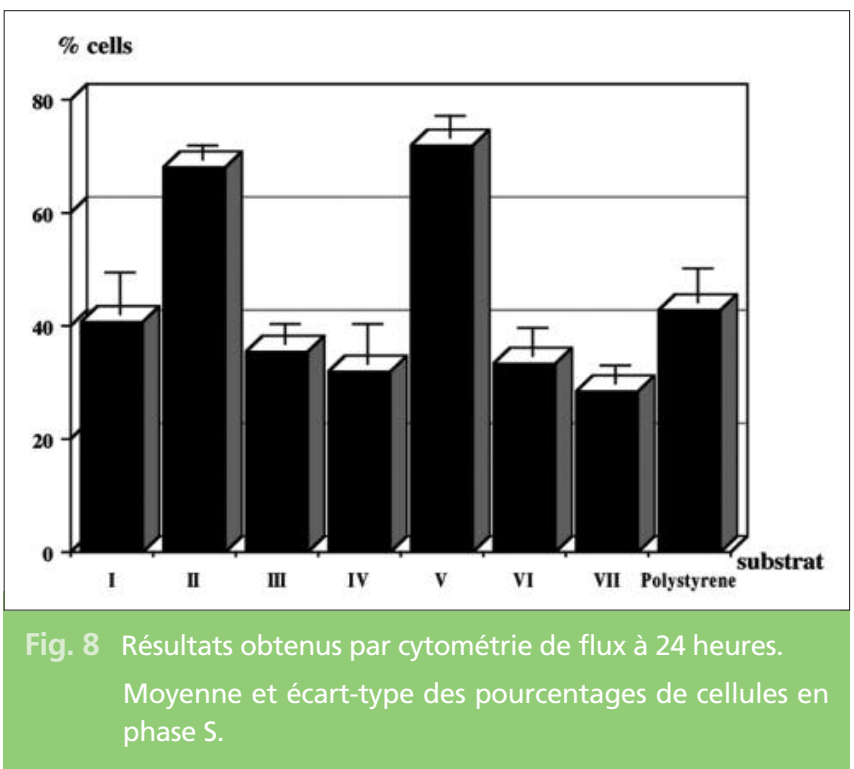

riaux), qui est respectivement de $67,9 \%$ et $71,8 \%$ avec une diminution des cellules en phase G0G1 et G2M par rapport aux autres matériaux.

Les résultats obtenus par cytométrie de flux à 72 heures sont représentés figure 9.

La cytométrie de flux montre à 72 heures une diminution de la prolifération marquée par une accumulation des cellules en phase G0G1 (64 à $70 \%$ ). Le témoin négatif, polystyrène de culture, présente $66 \pm 4,5 \%$ de cellules en phase G0G1, 21,9 $\pm 0,9 \%$ en phase $S$ et $10,5 \pm 1,9 \%$ de cellules en phase G2M.

La répartition des cellules dans le cycle est sensiblement égale. L'index de prolifération ( $\%$ de cellules en phase S) n'est pas statistiquement différent en ce qui concerne les matériaux II, IV, $\mathrm{V}$ et VII et le polystyrène de culture.

Après trois jours de culture, les plus faibles taux de multiplication cellulaire sont enregistrés avec I'échantillon I $(17,3 \pm 3,2 \%)$ et le VII. Ce dernier présente un pourcentage de cellules en phase duplicative $(12,2 \pm 2,9 \%)$ nettement inférieur à l'ensemble des autres supports $(p>0,05)$.

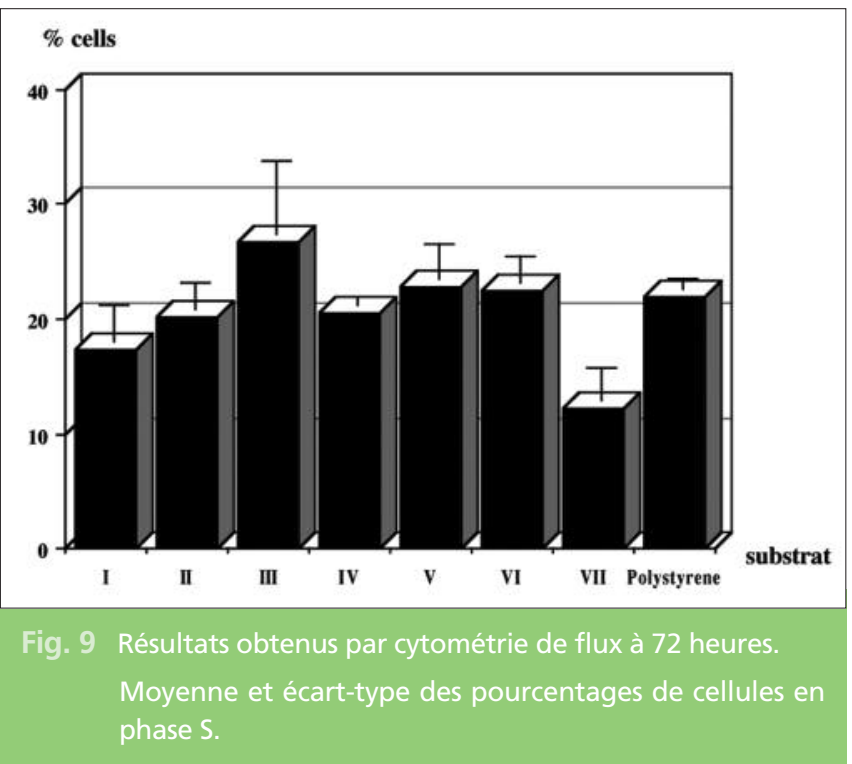


> Microscopie électronique à balayage

- À 24 heures, sur le polystyrène de culture, les cellules sont, en majorité, très étalées (fig. 10, $x$ 300) avec des prolongements cytoplasmiques permettant l'adhérence au substrat et entre elles.

Sur le polyuréthane, l'adhérence est faible, les cellules sont sphériques (fig. 11, x 300). Au fort grandissement, des altérations morphologiques sont détectables avec une absence de systèmes d'adhésions, les KB sont arrondies, et quelques fois regroupées en amas.

Pour l'ensemble des matériaux étudiés, la densité cellulaire est comprise entre celle obtenue
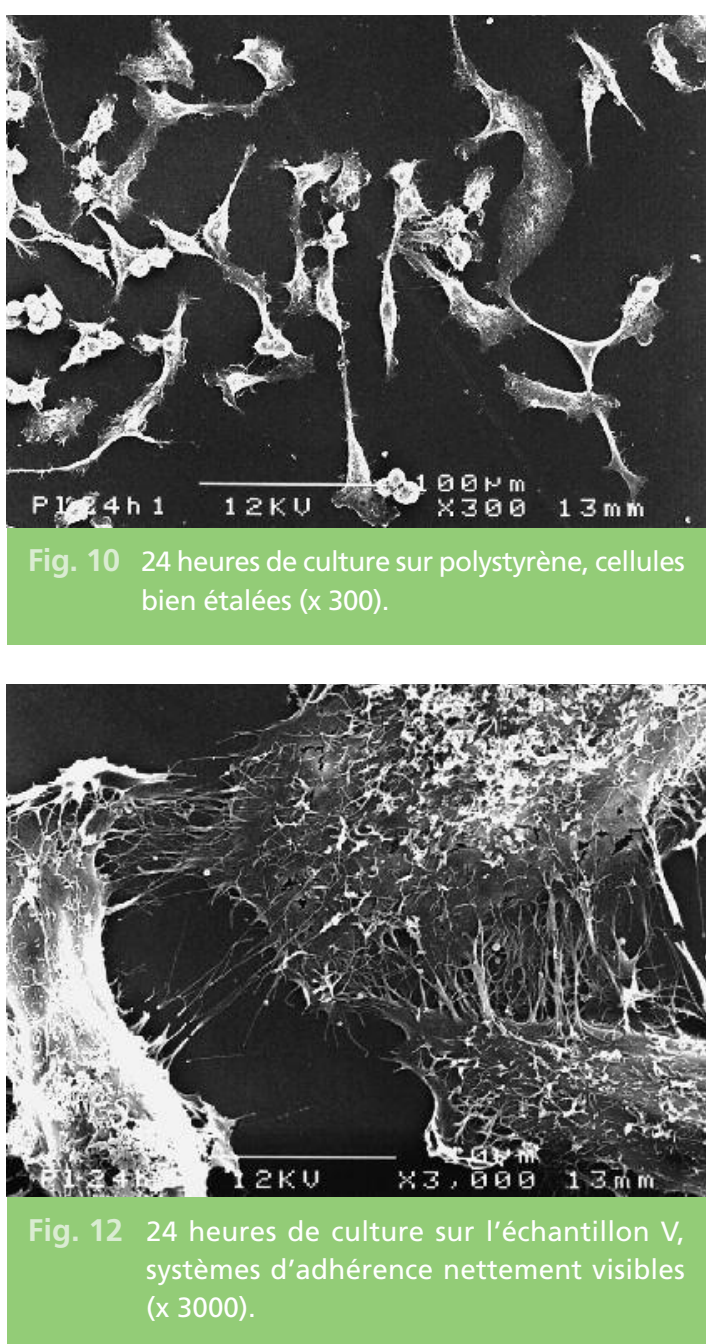

sur polystyrène et celle obtenue sur polyuréthane.

En ce qui concerne les matériaux commercialisés pour la fabrication des PDM, les cellules présentent un aspect relativement étalé bien que nettement moindre que sur le polystyrène (fig. 12, x 3000).

En revanche, les KB cultivées sur élastomères de silicone arborent peu de structure d'adhérence au substrat. Les cellules sont regroupées en amas avec une abondance de systèmes d'adhérence intercellulaires (fig. 13, x 3000).

- Après 72 heures de culture sur polystyrène, la densité cellulaire (fig. 14, x 300) est fortement
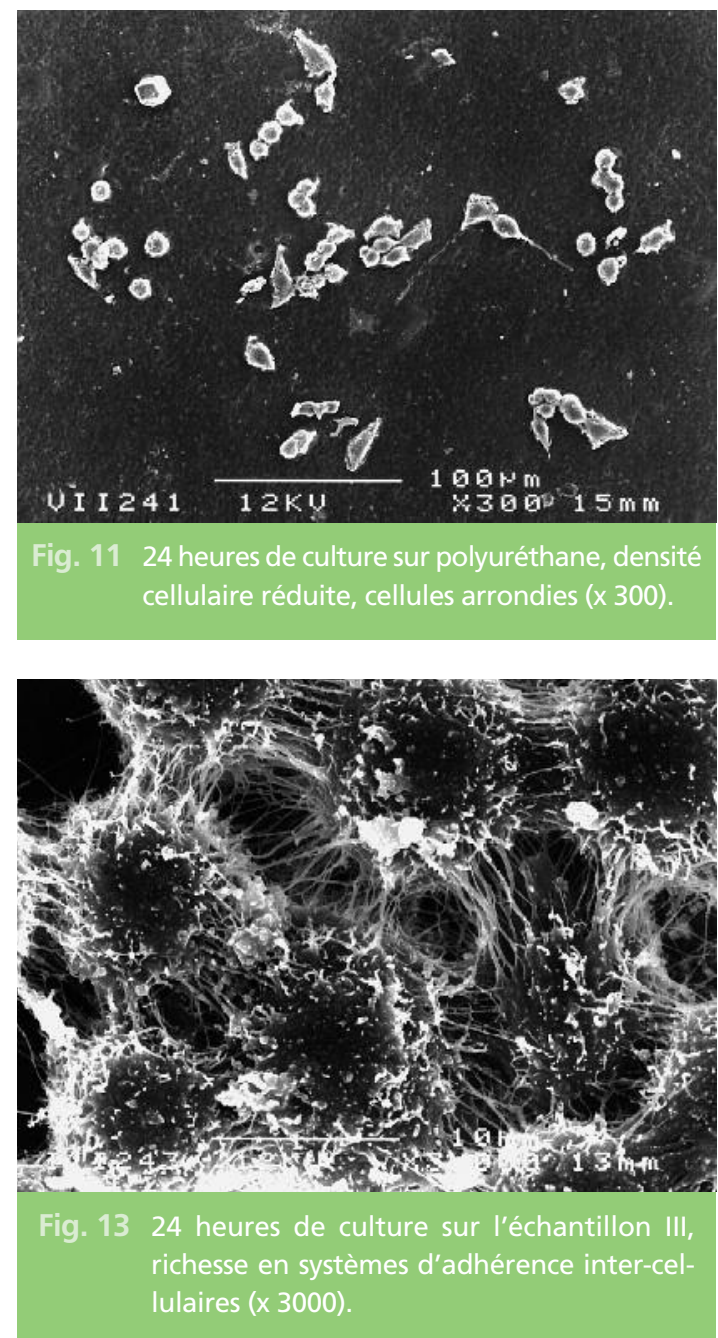


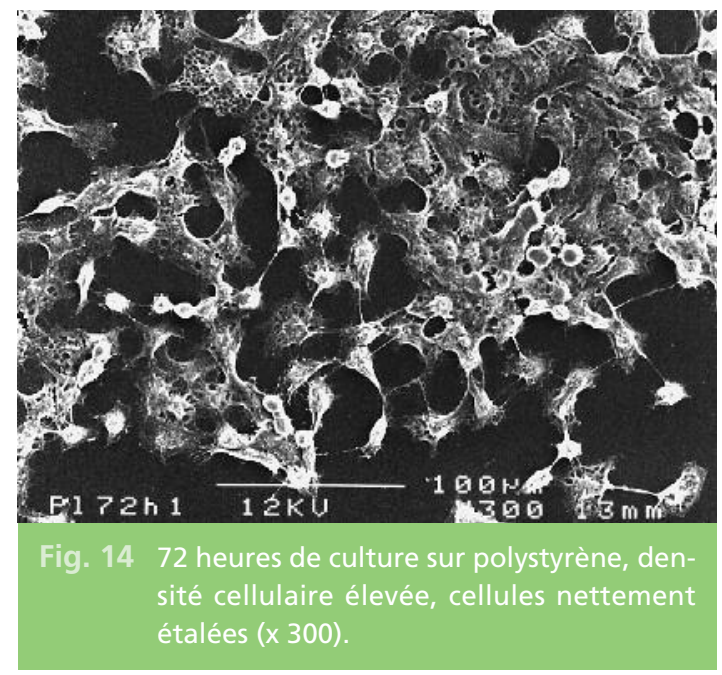

augmentée, et un aspect très étalé des kératinocytes est observé. Des systèmes d'adhérence arriment fortement les KB au substrat et relient les cellules entre elles.

Sur le polyuréthane, on observe une diminution importante du nombre des kératinocytes. Les rares entités cellulaires distinguables présentent une altération drastique de leur morphologie. Les KB sont arrondies, aucun système d'adhérence n'est discernable. Le boursouflement de la surface signe un état de souffrance cellulaire.

On retrouve pour les six matériaux testés, une densité cellulaire augmentée par rapport à l'expérimentation précédente, mais toujours inférieure à celle observée sur polystyrène de culture.

Les cultures sur matériaux commercialisés présentent, comme précédemment, un aspect relativement étalé. La densité cellulaire (fig. 15, x 300) est augmentée par rapport aux observations à 24 heures.

\section{Discussion}

Un matériau biocompatible est utilisé pour augmenter, traiter ou remplacer un organe ou

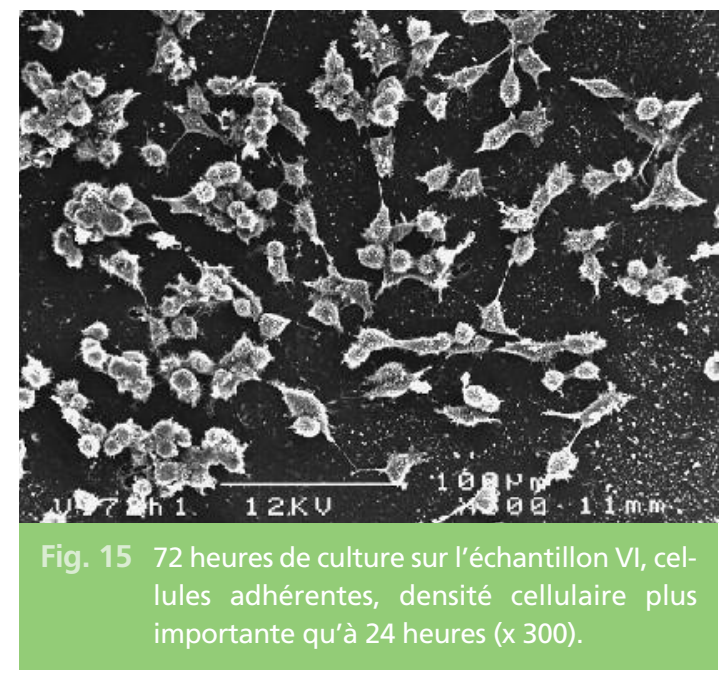

une fonction d'organe, et présente donc des relations avec les tissus vivants.

Les tests in vitro ne représentent qu'une étape, mais indispensable, à l'étude de la biocompatibilité d'un matériau. Ces tests doivent renseigner sur la mort, l'adhésion, la prolifération cellulaire ainsi que sur les altérations morphologiques et l'activité de biosynthèse [26].

La lignée KB utilisée dans cette étude est la seule lignée épithéliale d'origine buccale référencée à I'ATCC.

Ces cellules épithéliales ont été utilisées dans de nombreux travaux portant sur la génotoxicité [27] et la viabilité cellulaire [28, 29], en particulier en odontologie [30].

Nous avons écarté la stérilisation par chaleur, méthode de référence [31] du fait de la thermosensibilité de deux échantillons (V et VI) et des répercussions de cette méthode sur les propriétés des biomatériaux [32, 33].

L'oxyde d'éthylène, dont la fiabilité et l'efficacité $[34,35,31]$ ont été démontrées, présente I'inconvénient d'une toxicité résiduelle [34-37]. La stérilisation n'étant pas obligatoire pour ces matériaux destinés à la confection des protections dento-maxillaires, un protocole 
de "décontamination " a dû être mis en place afin de réaliser les investigations sur culture cellulaire. Ce protocole, utilisant des antibiotiques et antifongiques, et validé par des expérimentations préliminaires, a permis à tous les matériaux testés d'être dans des conditions identiques, sans modifier leur état de surface.

Dans cette étude, la viabilité cellulaire est évaluée par un test colorimétrique au MTT [24, 25 ], technique très sensible puisqu'elle permet la détection d'une différence de l'ordre de 1000 cellules. Cette quantification est infiniment plus précise que les tests couramment utilisés dans l'évaluation de la cytocompatibilité des matériaux, comme les techniques par contact direct ou par diffusion sur Agar [38, 39].

Contrairement à d'autres méthodes colorimétriques, comme le test à la sulforhodamine $B$, ce test au MTT donne des bruits de fond faibles qui se situent entre $0,15 \pm 0,01$ pour le plastique et $0,162 \pm 0,02$ pour les matériaux.

Enfin, ce test est d'un usage aisé, ne nécessitant pas de précautions particulières contrairement aux techniques faisant appel à des radio-isotopes.

L'utilisation de la cytométrie en flux pour évaluer la multiplication cellulaire représente une méthode précise et fiable car elle porte sur un grand nombre de cellules.

Cette méthode présente un avantage certain dans notre étude par rapport à des techniques:

- d'immuno-détection visant à mettre en évidence des anticorps nucléaires associés à la prolifération comme le Ki67 ou le PCNA ;

- de radio-détection étudiant l'incorporation de thymidine tritiée dont l'emploi s'avère difficile.
Le choix des témoins dans cette étude est conforté par les expérimentations. En effet, le nombre de cellules métaboliquement viables, en fonction de la DO, s'avère être significativement le plus élevé sur le polystyrène et le plus bas sur le polyuréthane, que ce soit après 24 ou 72 heures de contact.

Pour l'ensemble des échantillons, on assiste, par rapport à la référence, le polystyrène de culture, à une diminution du nombre de cellules (MTT) entre 24 et 72 heures. Celle-ci est corrélée à une réduction du pourcentage des cellules en phase $S$ (CFM).

À 24 heures, les différences observées, concernant les cellules viables, entre les échantillons et le polystyrène résultent essentiellement d'un déficit d'adhérence sur les élastomères, confirmée par le MEB. En effet, les densités cellulaires s'avèrent êtres moindres par rapport au polystyrène de culture, avec une adhérence plus faible des cellules au substrat conférant aux KB un aspect sphérique.

À 24 heures, seul le taux de viabilité de l'échantillon I est statistiquement comparable à celui du polystyrène avec en outre une prolifération identique (40\%). Ces résultats sont corroborés par le MEB qui révèle une densité cellulaire importante même si les cellules, d'aspect sphérique, se regroupent en amas, solidement ancrées les unes aux autres.

Le taux de prolifération sur ce même matériau reste semblable à celui du polystyrène (de $-23,4 \%$ à $-21 \%$ de cellules en phase $\mathrm{S}$ ). Après trois jours de culture, le différentiel concernant le nombre de cellules $(53,5 \%$ du polystyrène de culture) résulte donc essentiellement de la moindre adhérence initiale des KB. En ce qui concerne l'échantillon III, non commercialisé pour la confection des PDM, de composition proche du I, les résultats sont sensiblement identiques. Le nombre de cellules viables 
est légèrement inférieur ( $84,4 \%$ à 24 heures ; $52 \%$ à 72 heures) du fait d'une prolifération initiale moindre.

La multiplication cellulaire plus faible sur ces élastomères de silicone (I et III) par rapport au plastique a été rapportée dans l'étude de Hensten-Pettersen [38], concernant des primocultures de cellules épithéliales de rat. L'auteur ne met pas en évidence une moindre adhérence initiale sur ce support, la diminution de la biocompatibilité proviendrait d'une prolifération plus faible des cellules au contact de ce matériau.

Les contradictions avec d'autres travaux peuvent s'expliquer par la technique de culture utilisée. En effet, la méthode des explants pratiquée par l'auteur ne permet pas d'exclure la présence de cellules fibroblastiques contaminantes dont les sécrétions pourraient favoriser l'attachement initial des cellules épithéliales. En ce sens, un meilleur attachement des cellules épithéliales humaines et donc une diminution de la toxicité ont été obtenus par Hensten-Pettersen [38] en utilisant du talc, modifiant ainsi l'état de surface de cet élastomère de silicone. Cet auteur démontre de surcroît l'absence de relargage de substances toxiques par le MDX-4-4210. En effet, aucune variation de survie cellulaire n'est mise en évidence avec les matériaux ayant séjourné une semaine dans des bains de sérum physiologique afin d'éliminer toute substance toxique soluble.

La bonne biocompatibilité, in vivo, de ces biomatériaux (I et III) a été rapportée par Lucas [39], qui ne décèle aucune modification importante des tissus péri-implantaires. En outre, ce matériau I, présente une résistance importante aux facteurs environnementaux [40].

Les cultures de KB sur l'échantillon II conduisent à une viabilité de $75,7 \%$ à 24 heures et de
$61,1 \%$ à trois jours, un défaut d'adhérence initiale des cellules confirmé par le MEB et rapporté par l'étude de Hensten-Pettersen [38] sont à l'origine de cette différence de cytocompatibilité. II n'en demeure pas moins que ce biomatériau présente le plus grand taux de viabilité à 72 heures et cela grâce à une prolifération initiale importante $(2,5$ fois supérieure à celle observée sur polystyrène). Ces résultats sont en accord avec ceux réalisés in vitro par Polyzois [41, 42] et in vivo par Wolfaardt [43].

Les résultats concernant la cytocompatibilité des matériaux actuellement commercialisés pour la confection des PDM révèlent à 24 et 72 heures la supériorité de l'échantillon V. La viabilité, pour ce dernier, est de $86,9 \%$ à 24 heures et de $57,5 \%$ à 72 heures, avec une forte prolifération initiale, similaire à celle observée avec le support II. Une biocompatibilité plus faible est observée pour les deux autres élastomères, notamment pour le IV qui enregistre les plus faibles résultats de cette expérimentation.

En conclusion, les différentes techniques utilisées dans cette étude mettent en évidence :

- une biocompatibilité comparable entre un matériau (Plastulène) actuellement utilisé pour les PDM et les trois élastomères de silicone évalués (MDX-4-4210; Q7 48-40 et RTV 71556) ;

- une viabilité cellulaire moindre sur les deux autres produits commercialisés (SR-Ivocap ; Major-plast).

La biocompatibilité des composés de silicone est équivalente à celle du meilleur des trois produits actuellement commercialisés pour la confection des protections dento-maxillaires et étudiés dans ce travail. Ces élastomères de silicone constituent donc de bons candidats à l'élaboration de protection dento-maxillaire. 


\section{Conclusion}

Nous avons évalué et comparé les propriétés d'absorption des chocs et la dureté d'élastomères de silicone, de produits dérivés, et de produits habituellement utilisés pour la confection des protections dento-maxillaires.

Notre étude montre que les élastomères de silicone ont une meilleure capacité d'absorption des chocs que les matériaux habituellement utilisés pour la confection des protections dentomaxillaires.

Ces résultats associés à ceux de l'étude concernant leur biocompatibilité permettent de préconiser ces élastomères de silicone pour la confection des protections dento-maxillaires.

\section{Bibliographie}

1. Garon MW, Merokle A, Wright JT.

Mouth protectors

and oral trauma : a study

of adolescent football

players.

J Am Dent Assoc

1986;112:663-5.

2. Johnsen DC, Winters JE.

Prevention of intraoral trauma in sports. Dent Clin North Am 1991;35:657-66.

3. Kay EJ, Kakarla P, Macleod DA, McGlashan TP. Oro-facial and dental injuries in club rugby union players. Br J Sports Med 1990;24:271-3.

4. Guevara PA, Ranalli DN. Techniques for mouthguard fabrication. Dent Clin North Am 1991;35:667-82.

5. Keer IL.

Mouth guards for the prevention of injuries in contact sports. Vestal, New Zealand: Sport Medicine ADIS Press Ltd, U.S. Olympic Committee 1986;415-27.
6. Sametzky S. Protections dento-maxillaires (Mouth guards). Rev Odont Stomatol 1985,3:225-35.

7. Upson N. Mouthguards: an evaluation of two types for rugby players. Br J Sports Med 1985; 19:89-92.

8. Going $R E$, Loehman $R E$, Chan MS.

Mouthguard materials : their physical and mechanical properties.

J Am Dent Assoc 1974;89:132-8

9. Godeau P, Herson S, Piette J C.

Traité de Médecine. Paris, Flammarion, Médecine-Sciences, 1992.

10. Yamamoto $\mathrm{T}$.

Experimental studies on properties of mouth protector : evaluation of various materials dynamic energy absorption test with electrical shock sensor.
Tsurumi Shigaku, 1989;15:335-42.

11. Chretien $G$

Les materiaux composites à matrice organique. Paris, Editions Lavoisier Techniques et documentations, 1988.

12. Bishop BM, Davies EH, Von Fraunhofer JA. Materials for mouth protectors.

J Prosthet Dent 1985;53:256-61.

13. Craig RG, Godwin WC . Physical properties of materials for custom-made mouth protectors. J Mich State Dent Assoc 1967;49:34-40.

14. Hodgson V. Tolerance of the facial bones to impact. Am J Anat 1967;120:113-22.

15. Auroy $P$, Duchatelard $P$, Zmantar NE, Hennequin M. Hardness and shock absorption of silicone rubber for mouth guards. J Prosthet Dent 1996;75(4):463-71. 
16. Chauvel-Lebret DJ, Pellen-Mussi P, Auroy P, Bonnaure-Mallet M. Evaluation of the in vitro biocompatibility of various elastomers. Biomaterials 1999; Feb20(3),291-9.

17. Chaconas SJ, Caputo AA, Bakke NK.

A comparison of athletic mouth guard.

Am J Sports Med 1985;13:193-7.

18. Brionnet J.M., Roger V, Tubert S, Garson A. Comparative evaluation of rugby players satisfaction toward bimaxillary custom fitted mouthguards made with silicone or methylmetacrylate.

J Dent Res 1998;77, spécial issue $B$.

19. Woda A.

Abrégé de Physiologie Oro-Faciale Paris, Masson, 1983.

20. Oshima $\mathrm{H}$, Nakamura $M$. A study on reference standard for cytotoxicity assay of biomaterials. Biomed Mater Eng 1994;4:327-32.

21. Tsuchiya T.

Comparative studies of the toxicity of standard reference materials in various cytotoxic test and in vivo implantation tests. J Appl Biomater 1993;4:153-6.

22. Mosmann $\mathrm{T}$. Rapid colorimetric assay for cellular growth and survival: application to proliferation and cytotoxicity assays. $\mathrm{J}$ Immunol Methods 1983;65:55-63.
23. Ignatius $A A$, Claes LE. In vitro biocompatibility of bioresorbable polymers: poly (L, DL-lactide) and poly (L-lactide-co-glycolide). Biomaterials 1996;17:831-9.

24. Sgouras D, Duncan R. Methods for the evaluation of biocompatibility of soluble synthetic polymers which have potential for biomedical use. J Mater Sci - Mater Med 1990;1:61-8.

25. Smith MD, Barbenel JC, Courtney JM, Grant MH. Novel quantitative methods for the determination of biomaterial cytotoxicity. Int J Artif Organs 1992;15:191-4.

26. Kirkpatrick CJ, Mittermayer C. Theorical and practical aspects of testing potential biomaterials in vitro.

J Mater Sci - Mater Med 1990;1:9-13.

27. Cea G, Weigert G, Sepulveda R.

Genotoxic effects of erioflorin acetate and erioflorin methacrylate: sesquiterpene lactones isolated from podanthus ovatifolius lag.

(Compositae).

Bull Environ Contam Toxicol 1990;44:19-28.

28. Meshitsuka S, Ishizawa M, Nose T.

Uptake and toxic effects of heavy metal ions: interactions among cadmium, copper and zinc in cultured cells. Experimentia 1987;43:151-6.

29. Mochida K, Gomyoda M, Fujita T, Yamagata K. Toxicity of acrylonitrile on human KB cells

in culture.

Bull Environ Contam Toxicol 1989;42: 424-6.

30. Nakamura $\mathrm{H}$, et al. Study on the toxicity of root canal filling materials. J Endod 1986;12:156-60.

31. Goulet D.

La stérilisation des biomatériaux : quelle méthode choisir ? Agressologie 1992;33:121-3.

32. Jacob RFK, Collard SM. The effect of steam autoclave sterilization on methyl methacrylate cranial implant materials. Int J Prosthodont 1991;4:345-52.

33. Baier RE, Meyer AE, Akers CK, Natiella JR, Meenaghan M, Carter JM. Degradative effects of conventional steam sterilization on biomaterial surfaces. Biomaterials 1982;3: 241-5.

34. Gilding DK, Reed AM, Baskett SA.

Ethylene oxide sterilization: effect of polymer structure and sterilization conditions on residue levels. Biomaterials 1980;1:145-8.

35. Lyarskii PP, Likhtman TV, Kareyen NV, Komarkova NI, Gleiberman SE.

Physico-chemical and toxicologo-hygienic aspects of using ethylene oxide for the sterilization of medical appliances. J Hyg Epidemiol Microbiol Immunol 1984;2:119-28.

36. Gibson C, Matthews IP, Samuel AH.

Computerized model for accurate determination of ethylene oxide diffusion 
in sterilized medical supplies.

Biomaterials 1989;10:343-8.

37. Terezinha J, Pinto $A$, Saito T, lossif M.

Ethylene oxide sterilization: III-influence of carrier nature in a biological monitor performance. Technology/Applications 1994;48:155-8.

38. Hensten-Pettersen A, Hulterstrom A. Assessment of in vitro cytotoxicity of four RTV-silicone elastomers used for maxillo-facial prostheses. Acta Odontol Scand 1979;38:163-7.
39. Lucas MS, Moore DJ. Tissue culture and histologic study of a new elastomer. J Prosthet Dent 1979;42:447-51.

40. Mohite UH, Sandrik JL, Land MF, Byrne G. Environmental factors affecting mechanical properties of facial prosthetic elastomers. Int J Prosthodont 1994;7:479-86.

41. Polyzois GL, HenstenPettersen A, Kullmann A. An assessment of the physical properties and biocompatibility of three silicone elastomers.
J Prosthet Dent 1994;71:500-4.

42. Polyzois GL, Hensten-

Pettersen A.

Effects of RTC-silicone maxillofacial prosthetic elastomers on cell cultures. J Prosthet Dent 1994;71:505-10.

43. Wolfaardt JF, CleatonJones P, Lownie J,

Ackermann G. Biocompatibility testing of a silicone maxillofacial prosthetic elastomer: soft tissue study in primates. J Prosthet Dent 1992;68:331-8.

\section{SUMMARY}

\section{Silicone rubbers for mouth guards, physical and biological evaluation}

\author{
Pascal AUROY, \\ Dominique-Jane CHAUVEL-LEBRET, \\ Maurice MORENAS, \\ Jean-Luc VEYRUNE
}

\section{Keywords \\ - mouthguard \\ elastomer \\ - silicone \\ - hardness \\ - schok absorption \\ - biocompatibility \\ - flow cytometry \\ - cell adhesion \\ - cell survival \\ - microscopy}

Silicone rubbers have general properties that make them suitable for the fabrication of custom-made mouth guards. The first part of this study evaluated the shock absorption properties and Shore A hardness of several silicone rubbers and derived products, compared their values with those of materials commonly used for the manufacture of mouth guards, and correlated the shock absorption and transmission abilities of these different materials with their Shore hardness. Silicone rubbers absorb shock better than the materials currently used for custom-made mouth guards.

In addition, to adapt mouth guards to particular sports, the properties of the silicone rubbers can be appropriately modified by the addition of oils or glass fiber reinforcement.

Statistical analysis of hardess values and transmitted forces for the 27 materials tested indicates that the maximum transmitted force increases with hardness. However, this relationship is not linear, and departure from linearity is greatest for minimal and maximal hardness values.

In the second part we evaluated and compared the in vitro biocompatibility of silicone-based rubbers to propose them as an alternative to conventional products. We used the MTT colorimetric test to assess cell viability and flow cytometry to evaluate cell proliferation. Tests were conducted at 
24 and $72 \mathrm{~h}$. Changes in cell morphology were evaluated by scanning electron microscopy. Positive (polyurethane) and negative (polystyrene) toxicity controls were included. The number of viable cells was significantly higher on polystyrene than on polyurethane. A decrease in the total number of cells from 24 to $72 \mathrm{~h}$ compared to the negative control was correlated with a lower percentage of S-phase cells. The differences in cell viability noted between the samples and the polystyrene control mainly resulted from an initial lack of adhesion, which was confirmed by scanning electron microscopy. The biocompatibility of the three silicone rubbers was comparable to the best of the three products currently being used. These results, combined with those of the previous study, indicate that silicone rubber could be considered for the manufacture of mouth guards.

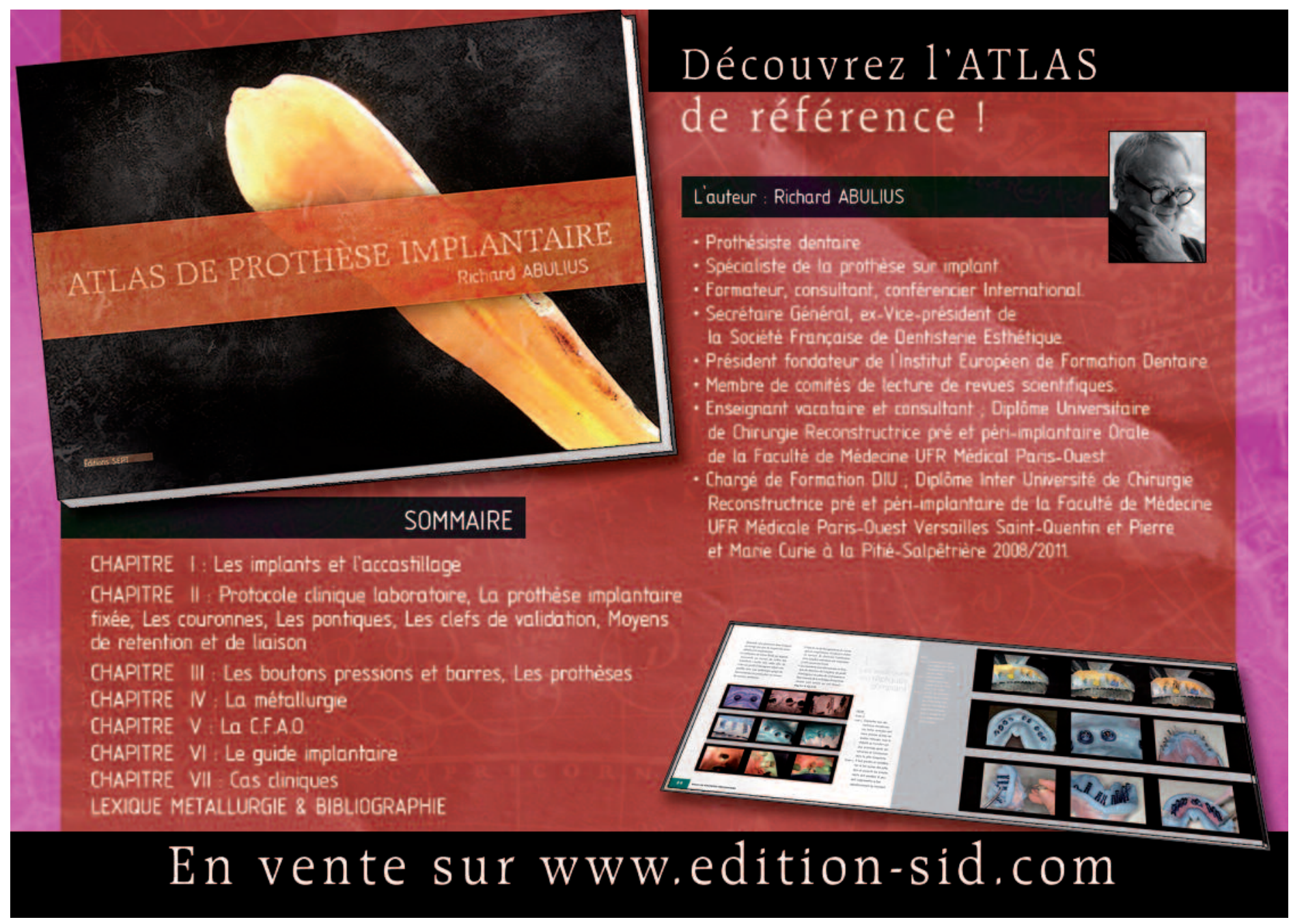

